\title{
BALANCE ECONÓMICO DEL TRASVASE TAJO-SEGURA
}

\author{
Joaquín Melgarejo Moreno*
}

\begin{abstract}
RESUMEN
La adecuación del trasvase Tajo-Segura a los criterios generales que sirven de base a la legislación que regula las transferencias de agua, el análisis de la política tarifaria y el balance económico de su gestión entre 1979 y 1995 son los principales temas que se abordan en este artículo. El modelo de explotación del Acueducto Tajo-Segura significó una ruptura en el sistema de financiación de las obras hidráulicas por el Estado, se perseguía que los usuarios fuesen los que corriesen con las inversiones y con los gastos de funcionamiento, buscando la autosuficiencia, al tiempo que la obtención de recursos adicionales para el cumplimiento de las obligaciones compensatorias con la cuenca cedente. La explotación del ATS y sus resultados económicos se han visto condicionados por la planificación de las obras y por la infrautilización que se ha venido haciendo de las mismas, lo que ha repercutido en un encarecimiento del agua conducida y ha servido para cuestionar la rentabilidad del trasvase.
\end{abstract}

\begin{abstract}
The main aims of this paper are the study of the degree of correspondence of the Tajo-Segura hydraulic transfer (TST) to the general criteria that are in the base of the legislation about water transfers, the analysis of tax policy and the economic imbalance of the TST management between 1979 and 1995. The exploitation model of TST meant a breakdown in the financing system of hydraulic works by the State. The aim was the customers to cover investments and ordinary expenses in a search for economic autonomy. At the same time one of the goals was to produce enough surpluses to economically compensate the institution that owned the transferred water originally. The exploitation of TST and its economic results have been conditioned by the planning of the works and by the underemployment that the built facilities have suffered, this factors leading to the rise of the price of transferred water and the questioning of TST economic results.
\end{abstract} Alicante.

Profesor Titular de Universidad del Departamento de Análisis Económico Aplicado. Universidad de 


\section{Introducción}

La planificación hidrológica es, sin lugar a dudas, la intervención estatal más incisiva en la gestión de las aguas y también la más polémica, sobre todo en lo que se refiere a los posibles trasvases intercuencas que se contemplan en el Plan Hidrológico Nacional, que aún no ha sido aprobado. En este sentido, los trasvases se configuran como la manifestación por excelencia de la planificación de las aguas en el ámbito nacional y significan la culminación de la progresiva intervención pública en la gestión hidráulica, una intervención que comenzó a materializarse en la segunda mitad del siglo XIX ${ }^{1}$. En efecto, el inicio de la planificación hidrológica supuso un cambio de tal magnitud que autores como A. Menéndez Rexach (1986: 629) lo han identificado como el final de la política hidráulica inspirada por Joaquín Costa y materializada por Manuel Lorenzo Pardo con la creación de las Confederaciones Hidrográficas. La planificación, en este sentido, supuso la superación de la cuenca como elemento de referencia en el diseño de la política hidráulica.

La fundamentación jurídica de los trasvases radica en la titularidad estatal sobre las aguas de dominio público, si bien el tema de la licitud de las transferencias entre cuencas es mucho más complejo, habida cuenta de sus implicaciones en la ordenación territorial de las zonas afectadas, en el medio ambiente y en las condiciones económicas y sociales. Así, los trasvases son en nuestro país objeto de una fuerte polémica: las zonas deficitarias intentan que éstos se realicen lo antes posible, aduciendo criterios de solidaridad y de equilibrio; mientras que las cedentes se oponen a las transferencias, alegando que no existen excedentes y que el recurso debe utilizarse en los lugares de origen para favorecer el desarrollo económico de estas zonas.

No fue casual que el primer trasvase intercuencas de la península Ibérica tuviese como destinatario de los caudales las tierras levantinas de la cuenca del Segura²; esta zona conjugaba la escasez permanente de recursos hídricos con su capacidad para crear riqueza. Los impulsores del trasvase consideraron implícitamente el agua como un factor de producción, en cuya asignación debía prevalecer la eficiencia; es decir, la utilización del recurso para las actividades que resultaran más productivas, que en este caso eran: una agricultura de exportación y altos rendimientos y el sector turístico ligado al litoral mediterráneo de las provincias de Murcia y Alicante. El Anteproyecto General del Aprovechamiento Conjunto de los recursos hidráulicos del Centro y Sureste de España se publicó en 1968, iniciándose las obras ese mismo año ${ }^{3}$. En

1 Sobre este proceso, puede verse J. Melgarejo (1995).

2 Al margen de otros antecedentes más remotos, la primera vez que se planteó la posibilidad de construir un trasvase para corregir el déficit hídrico de la región de Levante fue en el Plan Nacional de Obras Hidráulicas de 1933, los argumentos esgrimidos en su momento por el autor del Plan — Manuel Lorenzo Pardo- fueron retomados por todos aquellos que defendieron su construcción, entre los que tuvo un papel destacado el profesor Manuel de Torres, quien en su libro El regadío murciano, problema nacional (1959) reactivó la cuestión, siempre latente del trasvase, afirmando la rentabilidad de la obra y la oportunidad de realizarla. En lo sucesivo, los argumentos de la mayor productividad de las tierras del Segura, la mayor rentabilidad de las inversiones hidráulicas realizadas en esta cuenca y las repercusiones positivas que las obras tendrían sobre la economía nacional, vía balanza comercial, serían retomados para defender la ejecución de las obras del trasvase y su viabilidad. Para más detalle, véase J. Melgarejo (1993).

3 El trasvase como infraestructura consiste en el conjunto de obras e instalaciones destinadas a hacer posible el transporte y la distribución del agua procedente del Tajo a la cuenca del Segura. Siguiendo la clasificación de las obras que se hizo en el Anteproyecto General de 1968, éstas se dividen en tres grupos: el Pretrasvase, el Acueducto Tajo-Segura y el Postrasvase. El Pretrasvase es el conjunto de obras de regulación del alto Tajo y su cuenca. El Acueducto Tajo-Segura es la estructura básica del trasvase, mediante la cual se enlaza la cabecera del Tajo con el río Mundo, afluente del Segura; forman parte del ATS las obras comprendidas entre Bolarque y el embalse del Talave. Por último, el Postrasvase lo forman las obras realizadas en la cuenca del Segura para transportar y distribuir las aguas conducidas por el Acueducto por las zonas regables de la cuenca receptora. Para más detalle, J. Melgarejo (1993). 
1971 se aprobó la Ley del Aprovechamiento Conjunto Tajo-Segura. La Ley se fundamentaba en el principio de que las aguas públicas debían utilizarse allí donde su efecto resultara más beneficioso económica y socialmente para el conjunto de la nación y reconocía la capacidad del Estado para ordenar y fijar el destino del agua con independencia del marco físico de la cuenca por la que discurría de forma natural. Desde el punto de vista administrativo, suponía la superación de las Confederaciones como organismos encargados de gestionar las aguas públicas. También estaban presentes en la Ley de 1971 las cuestiones fundamentales de los trasvases: el reconocimiento de que sólo podían transferirse recursos excedentarios, el respeto a los aprovechamientos existentes y el derecho de la cuenca suministradora a recibir compensaciones por la cesión. En cuanto al régimen de explotación, se establecían dos fases: una primera, en la que se trasvasarían hasta $600 \mathrm{Hm}^{3}$, y la segunda, en que se llegaría a la cifra final de $1.000 \mathrm{Hm}^{3}$. Las obras básicas se finalizaron en 1978 y un año más tarde llegaban a la cuenca del Segura las primeras aguas del Tajo. Sin embargo, el inicio de la transición democrática y la creación del Estado de las Autonomías convirtieron al trasvase en el centro de una controversia que ha llegado hasta hoy enfrentando a la zona cedente y a la receptora ${ }^{4}$. Por su parte, el régimen económico de la explotación del Acueducto Tajo-Segura (ATS), que es el objeto de estudio de este artículo, se reguló mediante una Ley, promulgada el 4 de septiembre de 1980, que ordenaba el funcionamiento del trasvase buscando la autosuficiencia, al tiempo que imponía la obtención de recursos adicionales para el cumplimiento de las obligaciones compensatorias con la cuenca cedente.

El trasvase Tajo-Segura se sustentó en una serie de criterios generales que aparecen recogidos en la legislación que regula las transferencias de agua y que se asumen como la filosofía que debe presidir estas obras. Estos criterios básicos son: la titularidad estatal del dominio de las aguas y en virtud de ello la capacidad del Estado para planificar la utilización del recurso en beneficio de toda la sociedad; la protección de los derechos de la zona de origen, garantizando que sólo serán susceptibles de ser trasvasadas las aguas sobrantes o excedentarias y que deben establecerse compensaciones para la zona cedente ${ }^{5}$; y, por último, los trasvases deben cumplir determinados condicionantes económicos que avalen la rentabilidad de las obras: deben ser la fuente de menor coste para un suministro fiable de agua para el posible usuario ${ }^{6}$; sus beneficios han de superar todos los costes relacionados con ellos, es decir, las pérdidas de la zona de origen más los costes de construcción y funcionamiento; y nadie debe quedar en peor situación que antes con el proyecto. En este artículo trataré de comprobar en qué medida el trasvase Tajo-Segura se adecuó a estos criterios, analizando primero la política tarifaria y, más tarde, la gestión económica.

4 Sobre la polémica acerca del trasvase Tajo-Segura durante la transición democrática puede verse J. Melgarejo (1997).

5 Un caso bien diferente al ordenamiento español es el de los estados norteamericanos que se basan en la doctrina de la apropiación. Para éstos, no existe limitación alguna que circunscriba el uso del agua a la cuenca hidrográfica. Tal como se dictaminó en el primer caso de Colorado Coffin contra Letf Haud Ditch Co., el agua puede extraerse de la corriente y desviarse de la cuenca de origen para su uso en otras partes, aún cuando nada de ella retorne al sistema hidrológico originario. Con ello, los trasvases fuera de la cuenca se reconocen como legítimos, siempre que el agua se dedique a un uso beneficioso. Los usos futuros no están protegidos, por lo que puede afirmarse que la protección de la cuenca exportadora no es la característica del sistema de apropiación. Al respecto, puede verse L. Mac Donnell y Ch. W. Howe (1992).

6 Una vez desestimadas por inviables, en 1968, las alternativas basadas en el incremento del ritmo de explotación de los ya sobrexplotados acuíferos subterráneos y la desalinización de las aguas del mar, las aguas «excedentarias» del Tajo se definían como la opción de menor coste y mayor seguridad para incrementar los recursos hídricos de la cuenca del Segura. 


\section{La regulación jurídica de la explotación económica del trasvase Tajo-Segura}

A medida que se fueron finalizando las obras y que, por lo tanto, más cercana estaba la entrada en funcionamiento del ATS, las críticas y actuaciones en su contra desde la cuenca cedente arreciaron ${ }^{7}$. Ante la imposibilidad de dar marcha atrás al trasvase, las objeciones se centraron en el tema de las compensaciones y en la estimación de las aguas sobrantes. Las cuestiones esenciales del trasvase ya estaban planteadas en la Ley de 1971; sin embargo, la oposición desarrollada frente a esa Ley durante todo el período de ejecución de las obras aconsejó la promulgación de una nueva ley específica de regulación del régimen económico de la explotación del acueducto Tajo-Segura. En este contexto hay que situar la presentación ante las Cortes Generales del proyecto de ley sobre la explotación del acueducto, el cual iba precedido de un largo preámbulo o exposición de motivos, en el que se aludía al ATS como la mejor infraestructura hidráulica que se había acometido nunca en España para corregir el desequilibrio hidrológico y en el que se afirmaba que el trasvase no mermaría en ningún caso los derechos adquiridos. El objetivo básico de este proyecto de ley era ordenar el funcionamiento del ATS de tal forma que la gestión económica de la explotación y conservación de las instalaciones fuesen autosuficientes, al tiempo que se pretendía que se generaran recursos económicos adicionales con los que cumplir las previsiones contenidas el la Ley de 1971. Para conseguir tales fines, se establecía un sistema de tarifas, con las que se pretendía también introducir un principio de disciplina en el consumo de un bien escaso, fundamental y costoso. El proyecto de ley fue objeto de numerosas enmiendas en su tramitación. Finalmente, la Ley de régimen económico del trasvase fue aprobada por el Senado el 4 de septiembre de 1980. La enmienda admitida más importante fue la que garantizaba que nunca podrían ser trasvasables nada más que las aguas excedentarias determinadas por el Plan Hidrológico de la Cuenca del Tajo, sin que en el texto se definieran cuales debían ser consideradas como tales. Fue a partir de esta enmienda donde surgirían los problemas, al no delimitarse con claridad los excedentes de la cuenca de origen.

En efecto, la determinación de las aguas excedentes constituye el punto más conflictivo de esta Ley. El concepto de aguas excedentes puede ser entendido de distintas maneras, que esquemáticamente pueden reducirse a dos: o bien son excedentes los caudales que efectivamente no eran utilizados en el momento del trasvase, o bien se consideran las necesidades futuras de la cuenca suministradora, de manera que las aguas excedentes serían la diferencia entre el caudal del río y el preciso para atender estas necesidades potenciales. Tanto la Ley de 1971 como la de 1980 partían de este segundo concepto, aunque era recogido con mayor amplitud y generosidad por la segunda ${ }^{8}$. Por lo tanto, el trasvase sólo debía aplicarse a los sobrantes, lo que significaba que se debía garantizar en la cuenca cedente un caudal mínimo, que en la Ley de 1980 era de $6 \mathrm{~m}^{3} / \mathrm{seg}$ antes de la confluencia del Tajo con el Jarama. Esta Ley, en opinión de J.M. Martín Mendiluce (1989: 13), resultó ser «conceptualmente inteligente y posiblemente necesaria para hacer viable la explotación de una importante obra ya construida, pero filosóficamente puede ser objetable, ya que viene a consolidar el reconocimiento implícito que la Ley de 1971 suponía sobre un cierto derecho preferente de los ribereños de la cuenca del Tajo al agua circulante por sus cauces, circunstacia que contempla la ley de aguas anglosajona pero no

7 Véase J. Melgarejo (1997).

8 La Ley de 1980 aumentaba los aprovechamientos potenciales, incluyendo aquellos que fueran consecuencia del desarrollo natural de las provincias de la cuenca del Tajo. 
la española, y que ha sido tradicionalmente uno de los elementos diferenciales más característicos».

El verdadero interés de la Ley de 1980 radica en que en ella se marcaron las directrices económicas para establecer las tarifas de agua que debían abonar los usuarios. Estas directrices eran las siguientes: 1) Eliminar las subvenciones estatales para financiar la obra del ATS, al entender que los trasvases debían ser obras plenamente rentables. 2) Asignación de una parte de la tarifa a la realización de las obras compensatorias, en lo que quería ser el establecimiento de una corriente monetaria inversa a la seguida por los recursos trasvasados 9 . 3) Revisión de la tarifa cada dos años para actualizar de acuerdo con la inflación el coste de las obras ${ }^{10}$.

\section{La política tarifaria}

Íntimamente relacionada con el objetivo de que el trasvase fuese un proyecto rentable está la política tarifaria establecida para las aguas trasvasadas desde el Tajo al Segura, ya que sería mediante el cobro de tarifas a los usuarios como podría llegarse a rentabilizar las inversiones realizadas. Según A. González Romero y S.J. Rubio (1993: 33-66), tres eran los posibles criterios que podían adoptarse para fijar el precio del agua trasvasada: 1) la minimización de los costes de transporte del agua, 2) la fijación de tarifas iguales al coste de transporte medio, y 3) el criterio que ellos llaman de «maximización del bienestar social», que conlleva el establecimiento de tarifas socialmente óptimas. El primer enfoque se basa en el diseño de una política tarifaria que tiene como objetivo prioritario satisfacer las demandas de las cuencas deficitarias al mínimo coste. En relación con esta función de costes, se introducen dos argumentos: la distancia y el volumen de agua trasvasada, considerándose al primero como un parámetro y siendo la función de costes con respecto al segundo creciente y convexa. Bajo este criterio, la financiación de los costes corre a cargo de los presupuestos generales del Estado, mientras que en el usuario, vía tarifa, sólo recaen los gastos derivados del volumen de agua consumido y de la conducción de dicho volumen. El segundo internaliza el problema de la financiación de los trasvases y, para ello, se recurre a definir una política tarifaria sencilla que permita cubrir los costes de transporte en que se incurre, haciendo el beneficio cero. De esta manera, el coste total es financiado por los consumidores del recurso, sin que repercuta en los presupuestos generales del Estado. Las tarifas de agua estarían en función de los caudales trasvasados y se determinarían conjuntamente recurriendo a las funciones de beneficios. Mediante la tarifa el gobierno cubriría los costes, pero, además, obtendría unos ingresos adicionales iguales a la renta del recurso. El último de los tres enfoques persigue la implantación de unas tarifas que sean iguales al coste marginal del transporte del recurso. Con este sistema se trata de que el usuario financie, mediante la tarifa establecida, la totalidad de los costes de transporte

9 Las compensaciones, en este sentido, pueden ser consideradas como la aplicación del principio de equilibrio interregional reconocido en la Constitución de 1978. La Ley de 1971 regulaba con detalle un complejo sistema de compensaciones a la cuenca cedente, concretado en la transformación en regadío y otros aprovechamientos. La de 1980 iba más lejos, estableciendo de hecho un auténtico mecanismo de equilibrio horizontal entre las cuencas afectadas. Así, el artículo $6^{\circ}$ preveía que la cuarta parte de las tarifas de agua correspondiente al coste de las obras se destinaría a la realización con carácter prioritario de las acciones pendientes en la cuenca del Tajo y en las provincias de tránsito afectadas por el ATS. Independientemente de esto, el Estado se obligaba a la realización de tales obras.

10 En este sentido, el artículo $15^{\circ}$ resultó el más polémico, ya que establecía que las tarifas del agua podrían revisarse periódicamente en función de la actualización de los valores de las inversiones computadas como coste de las obras del acueducto. 
- como en el caso anterior-, pero que, además, se genere una renta social extraordinaria.

En el caso del Trasvase Tajo-Segura, se optó por el segundo enfoque: los usuarios financiarían, vía tarifa, los costes totales del trasvase; pero esta tarifa, al ser menor que la óptima, presentaba la ventaja de que tenía un menor coste político y podía ser aceptada más fácilmente por los afectados, al tiempo que, desde el punto de vista fiscal, seguía siendo positiva, ya que no exigiría ningún desembolso por parte del Estado para cubrir los costes de transporte. Por otra parte, las pérdidas de bienestar, por no aplicar la tarifa optima, se estimaban muy reducidas si se adoptaba la que igualaba el coste medio.

Ya en el Anteproyecto de 1968 se decía que las tarifas se establecerían en su día partiendo de los costes reales y se ofrecía a modo orientativo un precio del $\mathrm{m}^{3}$ de agua con destino a riego de 1,8 pesetas y para abastecimiento de 3,6. Una O.M. de 9 de agosto de 1971 establecía que las tarifas de riego serían iguales para todos los regadíos que se beneficiaran de las aguas procedentes del ATS y que las correspondientes a abastecimiento de poblaciones serían el doble de las de riego. Asimismo, la O.M. de 1971 revalidaba las directrices señaladas en el Anteproyecto para el cálculo de dichas tarifas, las cuales serían aplicadas hasta que se conocieran los importes reales de la totalidad de las obras ejecutadas. En 1979, el Ingeniero Jefe en funciones de la Confederación Hidrográfica del Segura (CHS) declaraba que el $\mathrm{m}^{3}$ de agua para riego costaría entre 4 y 5 pesetas, en la toma de los canales principales ${ }^{11} \mathrm{y}$, en ese mismo año, el Ministro de Obras Públicas afirmaba que, según los estudios técnicos del Ministerio, para amortizar la obra en 25 años debería cifrarse el precio del $\mathrm{m}^{3}$ en 4,66 pesetas ${ }^{12}$. Pocos días después de estas declaraciones, el 25 de mayo de 1979, el Consejo de Ministros autorizó las pruebas de gestión del ATS; en el texto de su aprobación se decía: «Con el objetivo de hacer coincidentes los intereses de la cuenca del Tajo con los de un aprovechamiento intensivo de sus caudales en el Sureste, resulta conveniente establecer como principio básico, el que la explotación del ATS genere recursos económicos que contribuyan al desarrollo de la política hidráulica del Estado en general y, de forma especifica y prioritaria, al de las acciones que prevé la Ley 21/1971, de 19 de junio, con lo que podrá adelantarse su ejecución $»^{13}$. En estas pruebas de gestión se establecían los siguientes precios para el agua en la red principal de conducción: 4 ptas $/ \mathrm{m}^{3}$ para regadíos y 8 para abastecimientos. Las cantidades obtenidas como resultado de la aplicación de dichas tarifas serían destinadas, en primer lugar, a atender los gastos del dispositivo hidráulico y las sobrantes se dedicarían a acelerar las inversiones compensatorias en la cuenca del Tajo y en las provincias de tránsito afectadas por el trasvase. En enero de 1980, por acuerdo del Consejo de Ministros, se prorrogaron las tarifas correspondientes a las pruebas de gestión hasta que entrase en vigor la Ley que regulaba el régimen económico del trasvase ${ }^{14}$.

La contestación por parte de los usuarios de las aguas trasvasadas no se hizo esperar. En la cuenca del Segura, hubo un rechazo unitario al precio estipulado para el agua de riego, amenazando algunos de los representantes de los regantes en la Confederación del

11 La Verdad de Murcia, 3-4-1979.

12 Información de Alicante, 19-5-1979.

13 Las llamadas obras de compensación fueron establecidas por los artículos $3^{\circ}, 4^{\circ}$ y $5^{\circ}$ de la Ley de 1971. Su realización ha sido estudiada por J.M. Sandoval Rodríguez (1989). Las compensaciones se concretaban básicamente en la transformación de regadíos, la construcción de una serie de presas reguladoras, el abastecimiento a pueblos afectados por el establecimiento de embalses y el trazado del acueducto y en la instalación de depuradoras.

14 La Ley de regulación del régimen económico de la explotación del Acueducto Tajo-Segura se aprobó el 16 de octubre de 1980 (BOE del 24-X-1980), entrando en vigor las tarifas correspondientes el 26 de agosto de 1981. 
Segura con dimitir, si no se llegaba a un acuerdo sobre este punto, aduciendo que las 4 ptas $/ \mathrm{m}^{3}$ se convertirían en 6, cuando a la primera cifra se les sumaran los gastos de distribución, mantenimiento y pérdidas por filtraciones y evaporaciones. El Subdirector General de Explotación del Ministerio de Obras Públicas —Rafael Fernández Ordóñezafirmó que «antes de comenzar a regar con el agua trasvasada del Tajo hay que pagar. Y hay que hacerlo a razón de $2 \mathrm{ptas} / \mathrm{m}^{3}$, como señal, hasta la liquidación final a 4 ptas». Estas declaraciones fueron interpretadas en Murcia como un nuevo triunfo de los intereses de la cuenca del Tajo y, en concreto, de las eléctricas, a las que consideraban como las grandes beneficiarias del trasvase. Así, apareció en la prensa regional un artículo, titulado «La guerra sobre el precio del agua del trasvase encierra muchos voltios ${ }^{15}$, en el que se recogían las opiniones de las principales comunidades de regantes beneficiarias de estas aguas. Según los regantes, el alto precio de la tarifa estipulada para riego era consecuencia de los elevados costes energéticos, planteando una posible solución que pasaría por invertir 7.000 millones de pesetas para incrementar la producción energética de las instalaciones del trasvase, hasta conseguir que el coste de funcionamiento del acueducto fuese negativo o nulo; con ello, el precio del agua sólo tendría que financiar la amortización de las inversiones realizadas -2 pesetas por $\mathrm{m}^{3}$ - ya que el resto de la tarifa estaba destinado a compensar la energía eléctrica que se dejaba de producir por la detracción de aguas del Tajo y la energía utilizada por el trasvase para las elevaciones. En el informe mencionado se aludía al hecho de que las centrales de Altomira, Alarcón-Picazo y Fontanar no podrían existir sin el ATS, por lo que, en opinión de los redactores del informe, los beneficios derivados de su aprovechamiento debían revertir en dicho acueducto.

La Confederación del Segura se mantuvo firme en la tarifa fijada, aceptando tan sólo que el pago pudiese diferirse, previa firma de un contrato que lo garantizase. Para los regantes esta forma de pago no sólo resultaba muy onerosa, sino que, además, rompía con la tradición existente en la cuenca, ya que los riegos siempre se habían abonado después de efectuados y nunca por adelantado. Ante la polémica suscitada, la Confederación del Segura explicó el desglose de la tarifa ${ }^{16}$, que ascendía a 4,676 ptas $/ \mathrm{m}^{3}$, si bien la Administración estableció el precio "político» de 4 ptas, dejando un margen de 67 céntimos para compensar cualquier error posible en los cálculos estimados. Sin embargo, esta explicación de la tarifa por parte de la Administración no acalló las protestas de los usuarios de la cuenca del Segura, que, por el contrario, se incrementaron con la presentación del proyecto de ley de explotación del trasvase y especialmente contra el artículo $7^{\circ}$. Los afectados

15 La Verdad de Murcia, 29-5-1979.

$16 \mathrm{El}$ desglose era el siguiente:

A) GASTOS FIJOS:

- Coste de las obras: $1,340 \mathrm{ptas} / \mathrm{m}^{3}$.

- Gastos fijos de funcionamiento, explotación y conservación del ATS: $0,494 \mathrm{ptas} / \mathrm{m}^{3}$.

- Explotación y conservación de las conducciones principales del Postrasvase: $0,351 \mathrm{ptas} / \mathrm{m}^{3}$. En este apartado se introducían los gastos derivados del establecimiento de vigilantes tanto del Postrasvase como del ATS y un porcentaje para preveer roturas; este último fue muy discutido, aunque, en opinión de la CHS, no suponía un incremento sustancial del precio final.

B) GASTOS VARIABLES:

- Gastos variables de funcionamiento en el ATS: $1,74 \mathrm{ptas} / \mathrm{m}^{3}$, que se convertían en 2,047 ptas $/ \mathrm{m}^{3}$ una vez que se tenían en cuenta las pérdidas a lo largo del canal, y se desglosaban de la siguiente manera:

- Canon de regulación a la CHT: $0,10 \mathrm{ptas} / \mathrm{m}^{3}$.

- Compensación a la CHT por la pérdida de energía reservada y cánones de pie de presa: 0,03 ptas $/ \mathrm{m}^{3}$.

- Bombeo de Altomira: 1,58 ptas $/ \mathrm{m}^{3}$.

- Compensación por el uso del túnel de Picazo: 0,03 ptas $/ \mathrm{m}^{3}$.

- Bombeos en el Postrasvase: 0,444 ptas $/ \mathrm{m}^{3}$. 
estimaban que el tratamiento dado al trasvase en cuanto a financiación era absolutamente atípico y comparativamente más gravoso que el otorgado a cualquier otra obra hidráulica construida con anterioridad. Las protestas se basaban en la aportación que se le exigía al usuario en concepto de coste de obra, que era de un $4 \%$ para riego y un $8 \%$ para abastecimiento, lo que era bastante superior a lo que se pagaría si la obra se hubiese financiado de acuerdo con lo dispuesto en la Ley de 7 de julio de 1911, sobre construcciones hidráulicas para riego, defensa y encauzamiento; la cual continuaba siendo el marco legal vigente para la financiación de este tipo de obras en nuestro país ${ }^{17}$. Los usuarios de las aguas del trasvase se sintieron discriminados por la Administración al establecer ésta la ruptura del principio de ayuda del Estado establecido en 1911, ya que se consideraraba, en este caso, que la inversión realizada debía ser satisfecha por los usuarios y, por lo tanto, no debía recaer sobre el conjunto de los contribuyentes. Pero, además, estas contribuciones de los beneficiarios no se planteaban teniendo un plazo de amortización, sino que el Estado percibiría esta aportación a perpetuidad, por lo que la titularidad de las obras efectuadas, aún cuando fuesen amortizadas en su totalidad, nunca revertirían en los usuarios, como ocurría con otras obras hidráulicas.

En este contexto, unas declaraciones del Director General de Obras Hidráulicas acerca de como debían financiarse las obras hidráulicas sirvieron para acrecentar la polémica y el malestar de los usuarios del trasvase. Juan Ruiz Pérez afirmaba que debía imponerse el realismo en cuanto a los precios de los servicios cuya prestación exigía importantes inversiones, no sólo para el primer establecimiento, sino para la conservación, mantenimiento y explotación adecuadas; siendo lo «razonable» —en su opinión- «postular que sea la infraestructura básica, cuyo beneficio es generalizado, donde se apliquen prioritariamente los presupuestos del Estado, cargando los costes de la infraestructura de uso y su gestión más directamente a los beneficiarios» ${ }^{18}$. Ello significaba que debía continuar la política de financiación de obras hidráulicas por parte del Estado, siguiendo las directrices marcadas por la Ley Gasset de 1911, con la única excepción del trasvase, ya que, en este caso, con las tarifas debían abonarse los costes de su infraestructura básica a perpetuidad, además de los de uso y gestión.

El precio del agua aparecía determinado en el artículo $7^{\circ}$ de la Ley, en el que se decía: «La tarifa incluirá las aportaciones motivadas por los siguientes conceptos: a) El coste de las obras. b) Los gastos fijos de funcionamiento. c) Los gastos variables de funcionamiento».

El concepto coste de las obras se obtenía como resultado de dividir el coste total de las obras realizadas ${ }^{19}$ entre la dotación total anual de agua trasvasada, afectado este resultado

17 En efecto, la Ley de 1911 regulaba en la práctica la actividad constructora del Estado en materia hidráulica, con o sin aportación de los interesados. Esta Ley establecía para el cálculo de la amortización de las obras hidráulicas un plazo de 25 años al 12,5\% de interés del 50\% de su importe total. Según los representantes de los usuarios, si se aplicaba dicha Ley a la financiación del trasvase, el abono del $4 \%$ anual sería el resultado de amortizar en 20 años el $60 \%$ de la obra, lo que efectivamente supondría un 3\% de amortización anual y la parte de intereses correspondiente, a razón de un $2 \%$ anual, que, a causa de la aplicación del sistema de amortización progresiva quedaría reducido al 1\% anual en el transcurso de los 20 años. En definitiva, según ésto, el $4 \%$ anual en 20 años completaría la aportación total de los usuarios por coste de la obra, lo que equivalía a decir que, cada 20 años, al no establecerse plazo de finalización para este pago, se abonaría el importe del trasvase.

18 Declaraciones recogidas en un suplemento de La Hoja del Lunes de Madrid, titulado «El Agua», aparecido el 14-7-1980.

19 Según el art. $2^{\circ}$ de la citada Ley, se consideraban obras del Acueducto Tajo-Segura «las ejecutadas o financiadas por el Estado para derivar, regular, conducir y distribuir las aguas trasvasadas, así como las obras complementarias necesarias para conseguir su perfecto funcionamiento». En el cómputo del coste de las obras se incluían los gastos motivados por la realización de los proyectos, la construcción, las expropiaciones e indemnizaciones necesarias, los edificios y caminos, los gastos de inspección y vigilancia y, en general, todas las inversiones realizadas. 
por un coeficiente que, en función del uso del agua, era del 0,04 en regadíos y del 0,08 en abastecimientos. Durante el período de explotación de la primera fase, limitada a un trasvase máximo anual de $600 \mathrm{Hm}^{3}$, se tendría en cuenta sólo el $60 \%$ del total de la inversión. El precio del agua destinada a abastecimientos se vería incrementado, además, con 2 pesetas por $\mathrm{m}^{3}$. Esta tarifa sería revisada cada dos años, en función de la actualización de los valores de las inversiones computadas.

La recaudación obtenida por este concepto se destinaría preferentemente a la realización de obras hidráulicas en la cuenca del Tajo, con independencia de los créditos consignados en los Presupuestos Generales del Estado para inversiones en esta zona, estableciendo el siguiente orden de preferencia $\left(\right.$ art. $\left.6^{\circ}\right)$ : 1) La realización con carácter prioritario de las acciones pendientes en la cuenca del Tajo y en las provincias de tránsito afectadas por el trasvase previstas en la Ley de $1971^{20}$, sin que ello fuera en menoscabo del compromiso asumido por el Estado para la realización urgente de tales obras. 2) La infraestructura hidráulica de las provincias de la cuenca cedente y las de tránsito del acueducto que no sean receptoras de agua. 3) El estudio y ejecución de nuevos trabajos de regulación, captación y uso combinado de aguas superficiales y subterráneas y de aquellos tendentes al ahorro de agua. 4) Una vez estuvieran cubiertas las necesidades anteriores, la recaudación sobrante podría destinarse a mejorar la infraestructura hidráulica de las provincias receptoras de agua o a cubrir el déficit de explotación, que se preveía que podía producirse en los primeros años de funcionamiento del trasvase. Sin embargo, esta posibilidad quedó anulada por acuerdo de Consejo de Ministros de 18 de abril de 1986. Por su parte, la cantidad recaudada en virtud del incremento de $2 \mathrm{ptas} / \mathrm{m}^{3}$ que afectaba a los volúmenes destinados a abastecimientos se destinaba a la realización de obras de ingeniería sanitaria hidráulica en la cuenca del Tajo y provincias de tránsito no receptoras.

El concepto coste de las obras fue el más contestado por los usuarios y el que suscitó una mayor polémica, junto con el que hacía referencia al uso de la energía. Ello obedeció, fundamentalmente, a tres razones: primera, porque esta cuota se establecía a perpetuidad, configurándose más como un peaje que cobraba el Estado por el uso de la infraestructura creada que como una amortización del costo de las obras realizadas, en contraposición a la legislación vigente sobre financiación de las obras hidráulicas, a la que ya me he referido. Segunda, porque se establecía en función del volumen de agua trasvasado, sin que se alterara el porcentaje del coste de la obra a financiar, lo que significaba que el $60 \%$ del costo de las obras debía ser abonado por los usuarios de los $\mathrm{m}^{3}$ trasvasados, de tal manera que a menor volumen trasvasado mayor coste por $\mathrm{m}^{3} \mathrm{y}$ viceversa. Como los desembalses anuales han estado y están muy por debajo del máximo establecido para la I ${ }^{\mathrm{a}}$ fase (como puede verse en el cuadro 8), la cuota por metro cúbico ha sido siempre muy superior a lo previsto inicialmente. Y, la tercera, que cerraba el cuadro de objecciones a este concepto, se basaba en el hecho de que se estableciese una revisión bianual del coste de la obra, para adecuar la inversión realizada a la inflación registrada, siendo ésta la primera y la única vez que se utilizaba por la Administración la actualización de las inversiones.

El segundo concepto que configuraba la tarifa del agua trasvasada era el derivado de los gastos fijos de funcionamiento. Esta parte de la tarifa era el resultado de dividir la previsión anual de los gastos de funcionamiento necesarios para efectuar la explotación de las obras — gastos que eran independientes del volumen trasvasado—, entre el total de dotaciones

20 En la disposición adicional tercera, se contemplaba la posibilidad de que las obras previstas en la Ley de 1971 pudiesen ser sustituidas por otras equivalentes o análogas, a petición razonada del órgano preautonómico o autonómico competente, previa propuesta de la correspondiente Diputación Provincial, y en determinados supuestos. 
asignado a las concesiones existentes. En dichos gastos se incluían los de mantenimiento del servicio, conservación de obras e instalaciones, administración y gestión.

Por último, los gastos variables de funcionamiento comprendían los de adquisición del agua, consumo de energía, servidumbres de paso y otros de naturaleza análoga ${ }^{21}$. Esta parte de la tarifa se obtenía dividiendo el valor de estos gastos entre el volumen de agua suministrada, por lo que era proporcional al consumo realmente producido, mientras que los dos valores anteriores se aplicaban a la dotación concesional. Los apartados más discutidos dentro de este concepto fueron la cuota por consumo de energía y la establecida a modo de canon por la utilización del túnel de Picazo.

En muchas ocasiones, el tema de las tarifas se planteó como un enfrentamiento entre dos intereses - el de los beneficiarios del trasvase y el de las centrales hidroeléctricas-, del que, según los usuarios levantinos, habían salido como ganadores las compañías hidroeléctricas ${ }^{22}$. No en vano, los gastos de energía eléctrica provocados por la elevación de Bolarque distorsionaban por entero el cálculo de la tarifa del ATS, por representar entre el 60 y el 70\% de la misma. Ello hizo que pidiesen una revisión de la fórmula concesional de Bolarque a Unión Fenosa. Por otra parte, desde el Segura también se culpaba a la Administración del elevado coste de los gastos variables, ya que en el Anteproyecto General se contemplaba la realización a lo largo del ATS de las centrales hidroeléctricas del Belmontejo, Alarcón, Villargordo y El Fontanar; y ninguna se construyó para disminuir la inversión a realizar. La construcción de estas centrales hubiera supuesto que el coste de funcionamiento del acueducto en concepto de la energía utilizada hubiese resultado nulo. Además, en el Anteproyecto se preveía también la construcción del túnel de Tébar, con origen en el contraembalse de Alarcón, para salvar el cañón del Júcar hasta el salto de Picazo; sin embargo, este túnel no llegó a construirse, optando la Administración por la utilización del túnel de Picazo que ya estaba construido y era propiedad de Hidroeléctrica Española, S.A., debiendo pagar las aguas del trasvase un peaje a esta empresa por la utilización de sus instalaciones, con el consiguiente encarecimiento del metro cúbico; a lo que se sumaba, además, la supeditación a que estaban sometidas las aguas del trasvase a las necesidades de Hidroeléctrica Española, lo que motivaba que los caudales no llegaran en muchas ocasiones en el momento requerido por los regantes ${ }^{23}$. Los usuarios de la cuenca

21 El coste de estos gastos variables era proporcional al volumen de agua suministrado. Incluía el canon de regulación de los embalses de Entrepeñas y Buendía y los costes que se originaban en la impulsión de Altomira, así como los derivados de las restantes impulsiones del postrasvase. Los costes de la impulsión de Altomira se calculaban según la fórmula polinómica que se estableció en la condición $9^{\mathrm{a}}$ de la concesión a Unión Fenosa del salto reversible de Altomira. La concesión databa de mayo de 1970 y en 1981 fue modificada la fórmula por el cambio de estructuras de las tarifas eléctricas. En esta fórmula se establecía el precio medio del servicio por situar un metro cúbico en el origen del canal. En él quedaban recogidas las compensaciones por pérdida de producción en las centrales situadas aguas abajo, el coste energético de la elevación, el de mantenimiento de la central reversible de Altomira y un incremento del $8 \%$ en concepto de gastos generales e interés del capital circulante (J.L. Nicolás Martínez, 1995: 139).

22 Así, el presidente del Sindicato Central de Riegos de la Vega Alta —José J. García Yelo_- afirmó, no sin cierta ironía: «El trasvase se hizo también para regar, no sólo para negocio de las compañías hidroeléctricas». (La Verdad, 26-2-1981)

23 En 1984, desde la CHS se planteaban dos alternativas para acabar con la situación de supeditación que sufrían las aguas del trasvase con respecto a la utilización del túnel de Picazo: una, la construcción del túnel de Tébar; dos, la adquisición por la explotación del trasvase de la central de Picazo, con lo que se dispondría por entero del túnel ya construido para la central. Esta segunda opción, sin embargo, chocaba con la política de aprovechamientos hidroeléctricos; por lo que sólo cabía dar prioridad a la construcción del túnel de Tébar y promover al tiempo la construcción del contraembalse de Cañaverosa, que permitiría regular $50 \mathrm{Hm}^{3}$. En cualquier caso, los usuarios del Segura pedían que Picazo o Tébar estuviesen a plena disposición del trasvase para que no limitaran o condicionaran su explotación. 
del Segura acusaban a la Administración de haber practicado una política miope que, por ahorrar inversiones en la creación de la infraestructura básica, había arbitrado soluciones que encarecían considerablemente la explotación de las obras y, por lo tanto, el $\mathrm{m}^{3}$ de agua trasvasada. Por último, los regantes del Segura criticaban a la Administración por haber elegido la opción del bombeo y elevación de las aguas en el postrasvase — más barata en inversión inicial - frente a la conducción por gravedad desde el pantano del Cenajo, que hubiera supuesto menor coste de explotación, al eliminar el uso de energía necesario para el bombeo ${ }^{24}$.

La suma de los tres conceptos analizados determinaba el precio del agua, que se establecía por bienios, con independencia del punto de toma. La obligación de satisfacer la tarifa nacía en el momento en que podían explotarse las instalaciones, una vez asignadas las dotaciones, quedando obligados al pago las entidades y las personas naturales o jurídicas que fuesen titulares de derecho al uso del agua. Además de esta tarifa, también se establecieron las bases para determinar la cuota que debían abonar los usuarios de las obras del trasvase con recursos propios, que utilizaran estas instalaciones para transportar y distribuir sus correspondientes dotaciones (art. $10^{\circ}$ de la Ley). Eran las denominadas aguas de peaje, a las cuales se les aplicaba una tarifa calculada de forma similar a la de las aguas trasvasadas, pero teniendo en cuenta sólo los gastos que afectaban al postrasvase ${ }^{25}$.

La aplicación de la política tarifaria se enmarca en dos etapas diferentes: la primera, denominada pruebas de gestión, abarca un período temporal que se extiende desde el 26 de mayo de 1979 hasta el 25 de agosto de 1981, el precio fijado para el agua de regadío fue de 4 ptas $/ \mathrm{m}^{3}$ y de 8 ptas $/ \mathrm{m}^{3}$ para el agua de abastecimiento a poblaciones; en la segunda, se aplicaba la Ley de 1980 y se fijaban las tarifas sucesivas aprobadas en acuerdos del Consejo de Ministros y publicadas en el Boletín Oficial del Estado. Como puede apreciarse en el cuadro 1, el precio del agua para riego ha variado de forma muy sensible desde la llegada de los primeros caudales trasvasados hasta 1995. Y también han variado sustancialmente las tarifas para abastecimientos y las de conducción de aguas propias de la cuenca del Segura.

En efecto, todas las tarifas experimentaron una fuerte subida a lo largo del período analizado. Todas más que duplicaron su valor entre el año 1981 y el año 1995, siendo las que gravaban el agua para riegos las que porcentualmente más se incrementaron, como puede verse en el cuadro 2, que muestra la evolución del precio de las tarifas en números

24 Con anterioridad, incluso, al anteproyecto de postrasvase se plantearon dos opciones para posibilitar la distribución de las aguas del Tajo en la cuenca del Segura. En síntesis, la opción A se basaba en que los canales de derivación partieran de los embalses ya construidos sobre el río Mundo - Talave y Camarillas —, comunicando con un túnel el embalse del Talave con el Cenajo; desde el Camarillas partiría el canal de la margen izquierda y desde el Cenajo el de la margen derecha. La opción B situaba el punto de toma para el agua trasvasada en el cauce del Segura, en Ojós, donde se construiría un embalse que serviría de punto de arranque para los dos canales principales: uno tomaría el agua mediante bombeo (el de la margen derecha) y el otro por gravedad hasta el punto de destino (el de la margen izquierda). El Ministerio de Obras Públicas adoptó la segunda opción (B), lo que le supuso un ahorro en la inversión necesaria próximo a los 4.000 millones de pesetas con respecto a la opción A; pero, por contra, supuso el abandono de la posibilidad de abastecer por gravedad a las zonas que tenían caudales asignados. (J. Melgarejo, 1993: 569-570).

25 Así, por ejemplo, el valor 0,92 del año 1986 para las aguas propias, en función del concepto «coste de las obras», resultaba de la estimación del costo del postrasvase en 27.110 millones de pesetas, cantidad que debía amortizarse en un $60 \%$ por estar en marcha sólo la I $\mathrm{I}^{\mathrm{a}}$ fase, aplicándosele el coeficiente 0,04 correspondiente a regadíos, y teniéndose en cuenta que habían circulado por la infraestructura del trasvase $196 \mathrm{Hm}^{3}$ de agua de la cuenca. El resultado de este concepto para las aguas travasadas en ese mismo año era de 3,02, como resultado de estimar el costo de las obras del trasvase y del postrasvase en 71.833 millones de pesetas, en diciembre de 1985 . Los datos sobre la estimación de las obras del trasvase y del postrasvase están tomados de C. Juárez SánchezRubio (1991: 57). 


\section{Cuadro 1}

EVOLUCIÓN DE LA TARIFAS DE CONDUCCIÓN DEL AGUA, 1979-1995. En Ptas/m³.

\begin{tabular}{|l|c|c|c|c|}
\hline & \multicolumn{2}{|c|}{ AGUAS TRASVASADAS } & \multicolumn{2}{c|}{ AGUAS PROPIAS } \\
\hline & Riegos & Abastecimientos & Riegos & Abastecimientos \\
\hline Pruebas de gestión (1979-1981) & 4,00 & 8,00 & - & - \\
\hline $1981-1982$ & 6,21 & 9,50 & 2,00 & 3,09 \\
\hline $1982-1985$ & 6,54 & 9,83 & 2,00 & 3,09 \\
\hline $1985-1986$ & 9,55 & 12,99 & 3,17 & 4,38 \\
\hline $1986-1987$ & 11,70 & 16,73 & 3,16 & 5,49 \\
\hline $1987-1989$ & 11,70 & 16,77 & 3,11 & 4,67 \\
\hline $1989-1995$ & 13,68 & 18,55 & 4,86 & 6,36 \\
\hline 1995 & 18,23 & 23,99 & 6,23 & 9,41 \\
\hline
\end{tabular}

FUENTE: Departamento de Gestión del ATS (CHS).

índices, tomando como base 100 la correspondiente al año 1981. Si atendemos al tipo de agua trasvasada, fueron las que afectaban a la conducción de aguas propias de la cuenca del Segura las que mayor crecimiento relativo experimentaron. El primer incremento se produjo con la aprobación de las tarifas para el bienio 1981-82, que supuso una subida del precio del agua del $55 \%$ para el riego y del $18 \%$ para el abastecimiento; pero debe tenerse en cuenta que el precio fijado para el período de «pruebas de gestión» había respondido a criterios «políticos» y no reflejaba en su totalidad el coste real del agua trasvasada. Las tarifas fijadas para 1982-85 apenas cambiaron, ya que sólo significaron un pequeño incremento del precio del agua trasvasada, manteniéndose estable el coste de la conducción de aguas propias. Sin embargo, las tarifas aprobadas en abril de 1985 produjeron una fuerte subida del precio del agua del ATS (46\% para la destinada a riegos y $32 \%$ para la de abastecimientos), que aún fue mayor en el caso de los recursos propios (58\% para la de riegos y $41 \%$ para la de abastecimientos). Esta subida se debió, como puede verse en el cuadro 3 , a un considerable aumento de los gastos variables, principalmente, del coste energético. La revisión del coste de las obras, que se hizo en diciembre de $1985^{26}$, conllevó una nueva subida de las tarifas establecidas para 1986-8727, duplicándose la cuota correspondiente al concepto a) de la tarifa (cuadro 3). La tarifa establecida en agosto de 1987 estabilizó el precio del agua del ATS y rebajó los cánones de conducción de los recursos propios de la cuenca del Segura; ello se debió a la reducción del componente c) de la tarifa (cuadro 3) y, fundamentalmente, al apartado correspondiente a los gastos por consumo de energía, debido a que el Director Técnico de la CHS, ante la presión de los usuarios, logró la aceptación de una interpretación de la fórmula concesional de Unión Fenosa por la que

26 El MOPU actualizó el valor de las obras del trasvase y del postrasvase, estimándolo en 71.833 millones de pesetas. Una nueva revisión fue realizada en 1997, evaluándose el coste en 90.000 millones de pesetas (La Verdad, 18-2-1998).

27 Los incrementos a los que nos referimos fueron del $22 \%$ para las aguas de regadío del trasvase, $29 \%$ para las de abastecimiento y $25 \%$ para las de abastecimiento de la cuenca del Segura. 
fue posible reducir los gastos de elevación de Bolarque; lo que permitió moderar la subida de la tarifa establecida ese año. Esta negociación abrió una etapa de autosuficiencia en la gestión del trasvase; sin embargo, con posterioridad, el problema de la aplicación del IVA ${ }^{28}$ y la falta de acuerdo para lograr una revisión de la fórmula concesional de Unión Fenosa dificultaron el cálculo de nuevas tarifas, las cuales eran necesarias para mantener la autosuficiencia. Se corrió, a finales de 1987, el riesgo de volver a una situación deficitaria. Esta tendencia se interrumpió con la aprobación de una nueva tarifa en 1989 —en vigor hasta 1995-, que volvió a incrementar el precio del agua, una subida que fue especialmente fuerte en el caso de las aguas del Segura que utilizaban la infraestructura del postrasvase (los incrementos fueron del 16\%, 10\%, 56\% y 36\%). En 1995, se aprobó la última de las tarifas analizadas en este trabajo, que significó un nueva subida del coste del agua trasvasada $(33 \%, 29 \%, 28 \%$ y 47\%). En ambos casos se debió al alza del precio de la energía utilizada para bombear los recursos ${ }^{29}$.

\author{
Cuadro 2 \\ EVOLUCIÓN DE LOS ÍNDICES DE LAS TARIFAS DEL ATS, 1981-1995. \\ (Índice base 100 en 1981)
}

\begin{tabular}{|llllllll|}
\hline & $\mathbf{1 9 8 1}$ & $\mathbf{1 9 8 2}$ & $\mathbf{1 9 8 5}$ & $\mathbf{1 9 8 6}$ & $\mathbf{1 9 8 7}$ & $\mathbf{1 9 8 9}$ & $\mathbf{1 9 9 5}$ \\
\hline ART ...... & 100 & 105 & 154 & 188 & 188 & 220 & 304 \\
AAT ...... & 100 & 103 & 137 & 176 & 176 & 195 & 253 \\
ARS ..... & 100 & 100 & 158 & 158 & 155 & 243 & 312 \\
AAS...... & 100 & 100 & 142 & 178 & 151 & 206 & 305 \\
\hline
\end{tabular}

ART: Tarifa para el agua del ATS destinada a riegos.

AAT: Tarifa para el agua del ATS destinada a abastecimientos.

ARS: Tarifa de conducción de las aguas propias de la cuenca del Segura para riegos.

AAS: Tarifa de conducción de las aguas propias de la cuenca del Segura para abastecimientos.

Fuente: Cuadro 1.

Como puede apreciarse en el cuadro 3, todos los conceptos experimentaron fuertes subidas, casi triplicándose su cuantía en la mayoría de los casos. Los gastos fijos representaban la menor parte de las tarifas y su mayor incremento se produjo entre 1981 y 1985, para después crecer de forma moderada; buena muestra de la ponderación de este concepto

28 A finales de 1986, se produjo una resolución de la Dirección General de Tributos declarando sujetos al IVA los cánones de regulación y las tarifas de riego. De acuerdo con la orden de la DGT, el presidente de la CHS decidió que se consideraran base imponible únicamente los gastos fijos y variables de funcionamiento (no la aportación al coste de las obras) y no desde Bolarque, sino sólo desde el Talave. La razón esgrimida fue que se estimó que la conducción desde Bolarque hasta el Talave era función estatal de planificación hidrológica para equilibrar dos regiones en sus recursos hídricos, aduciendo el artículo $131^{\circ}$ de la Constitución y el $38^{\circ}$ de la Ley de Aguas, y no servicio prestado por las Confederaciones, cuya contraprestación debía estar sujeta al IVA. Sin embargo, el interventor no aceptó esta aplicación y la suspendió. Finalmente, la DGT decidió que no estaban sujetos al IVA los cánones de regulación ni las tarifas de riego, incluida la del trasvase. Esta nueva decisión estuvo motivada por la reclamación de los regantes. Sin embargo, se consideró que la Confederación debía pagar el IVA a sus proveedores; en especial, a los suministradores de energía eléctrica (que era el componente más importante de la tarifa) y que debía repercutirse en el cálculo de los mismos cánones o tarifas, con lo cual los regantes pagarían indirectamente el IVA que parecía que no les afectaba. (E. Pérez, 1988).

29 Según V. Caballer y N. Guadalajara (1998: 34), entre 1981 y 1996 se produjo un incremento anual de 50 céntimos por kw en las tarifas eléctricas. 
es el hecho de que este apartado no fuese contestado en ningún momento por los usuarios levantinos. Por el contrario, fueron las aportaciones correspondientes al costo de las obras y a los gastos variables los que configuraban el grueso de las tarifas, siendo, asimismo, las que levantarían más protestas por parte de los usuarios. Ambos conceptos experimentaron un notable incremento a lo largo del período reseñado: el a) prácticamente se duplicó entre el año 1985 y el 1986, como consecuencia de la revisión que el MOPU hizo en diciembre de 1985 del valor del costo de las obras; a partir de la tarifa de 1986, la aportación económica que debían satisfacer los beneficiarios del trasvase por el costo de las obras se alteraría de forma muy poco significativa, con pequeñas subidas en 1987 y 1995 y un descenso en 1989, debidas a la variación de los volúmenes desembalsados. Los gastos variables fueron, en el caso de las tarifas del agua para riego, los que determinaban en mayor medida su cuantía - entre el 60 y el $70 \%$ de la tarifa-, mientras que en la de abastecimientos su importancia, aunque significativa, fue menor -entre el $40 \mathrm{y}$ el $50 \%$-, debido al peso que en esta última suponía el pago por el coste de las obras. Los costes energéticos de la elevación del agua constituían la mayor parte de los gastos variables, siendo los principales causantes de la elevación del precio del $\mathrm{m}^{3}$ de agua para regadío ${ }^{30}$. Por ello, los regantes con el objeto de abaratar las tarifas reclamaban la concesión de una serie de saltos de agua para producir energía punta, con esto esperaban controlar las tarifas de riego y obtener el agua a un precio mucho más bajo, haciendo más rentable el metro cúbico utilizado. Para los usuarios del Segura estaba claro, el desaprovechamiento energético que se hacía del acueducto Tajo-Segura, por no haberse construido las cuatro centrales hidroeléctricas previstas en el anteproyecto general de aprovechamiento conjunto TajoSegura (Belmontejo, Alarcón, Villargordo y El Fontanar) era la principal causa del encarecimiento del precio del agua.

Las protestas de los usuarios contra las tarifas surgieron desde el primer momento, encauzándose a través de lo que posteriormente sería el Sindicato Central de Regantes del

30 En un trabajo publicado por la Consejería de Política Territorial y Obras Públicas de la Comunidad Autónoma de Murcia en 1984, titulado El aprovechamiento energético de los recursos hidráulicos en la cuenca del Segura y los relacionados con la explotación del trasvase Tajo-Segura, se realizaba un estudio de la explotación de la central de Bolarque II (Altomira), del cual se desprendía que el máximo beneficio inmediato se producía no trasvasando agua al Segura, sino utilizándola únicamente con fines hidroeléctricos. A partir de ese caudal cero, el beneficio iba disminuyendo a medida que crecía el volumen trasvasado, haciéndose nulo sobre los $10 \mathrm{~m}^{3} / \mathrm{seg}$., a partir del cual la compañía eléctrica debía adelantar energía, ya que el consumo superaba a la turbinación. De este hecho se derivaba que de las $6,54 \mathrm{ptas} / \mathrm{m}^{3}$ de agua trasvasada para riegos — precio establecido en la tarifa de 1982 - , 4,52 ptas — casi el 70\% — se destinaran a compensar a Unión Eléctrica Española, que era la concesionaria de la central Bolarque-Altomira, por las pérdidas que suponía cuando se producían trasvases de agua al acueducto. El estudio concluía resaltando que en tales circunstancias resultaba más cara la elevación del $\mathrm{m}^{3}$ trasvasado que la compra de la energía al precio general del mercado.

En este contexto, hay que encuadrar la propuesta hecha en 1981 por Pérez Crespo acerca de la central de Bolarque, que había sido construida por Unión Eléctrica S.A. con la colaboración del Estado. El costo de la obra se evaluaba en 3.000 millones de pesetas, de los cuales la aportación de Unión Eléctrica era de 1.300 millones (el $43,4 \%$ ) y la del Estado de 1.700 (56,6\%), los cuales estaban siendo amortizados por los usuarios de la cuenca del Segura, sin que ello supusiera el derecho a beneficiarse de dicha obra; ante lo cual, la propuesta de Pérez Crespo fue la de amortizar el conjunto de la obra - lo que significaría un incremento del precio del $\mathrm{m} 3$ de agua de 6 céntimos-y que fueran los usuarios de la cuenca del Segura los beneficiarios de la venta de energía en la central de Bolarque II o que, puesto que éstos amortizaban el 56,6\% del costo de la obra, que participaran de los beneficios que produce dicha central en la misma proporción. Ante la pregunta que el Senador Pérez Crespo hizo al Ministro de Obras Públicas, Luis Ortiz, sobre si los usuarios de la cuenca del Segura se beneficiarían de la central de Bolarque II, éste respondió que no, con lo que quedó zanjada la cuestión. 


\section{Cuadro 3}

\section{DESGLOSE POR CONCEPTOS DE LAS TARIFAS DE CONDUCCIÓN DEL AGUA $\left(\right.$ Ptas $\left./ m^{3}\right)$}

\begin{tabular}{|c|c|c|c|c|c|c|c|c|c|c|c|c|}
\hline \multicolumn{13}{|c|}{ AGUAS DEL TRASVASE: } \\
\hline & \multicolumn{2}{|c|}{1981} & \multicolumn{2}{|c|}{1985} & \multicolumn{2}{|c|}{1986} & \multicolumn{2}{|c|}{1987} & \multicolumn{2}{|c|}{1989} & \multicolumn{2}{|c|}{1995} \\
\hline & Reg. & Abast. & Reg. & Abast. & Reg. & Abast. & Reg. & Abast. & Reg. & Abast. & Reg. & Abast. \\
\hline A & 1,29 & 4,58 & 1,44 & 4,88 & 3,02 & 8,05 & 3,06 & 8,13 & 2,86 & 7,72 & 3,79 & 9,58 \\
\hline B & 0,73 & 0,73 & 1,31 & 1,31 & 1,45 & 1,45 & 1,68 & 1,68 & 2,00 & 2,00 & 3,04 & 3,04 \\
\hline \multirow[t]{2}{*}{$\mathrm{C}$} & 4,19 & 4,19 & 6,80 & 6,80 & 7,23 & 7,23 & 6,96 & 6,96 & 8,82 & 9,13 & 11,4 & 11,37 \\
\hline & 6,21 & 9,50 & 9,55 & 12,99 & 11,70 & 16,73 & 11,70 & 16,77 & 13,68 & 18,85 & 18,23 & 23,99 \\
\hline \multicolumn{13}{|c|}{ AGUAS PROPIAS DE LA CUENCA DEL SEGURA: } \\
\hline A & 0,42 & 1,51 & 0,51 & 1,72 & 0,92 & 2,45 & 0,94 & 2,50 & 0,88 & 2,38 & 1,18 & 4,37 \\
\hline B & 0,27 & 0,27 & 0,60 & 0,60 & 0,65 & 0,65 & 0,67 & 0,67 & 1,27 & 1,27 & 1,21 & 1,20 \\
\hline \multirow[t]{2}{*}{$\mathrm{C}$} & 1,31 & 1,31 & 2,06 & 2,06 & 2,39 & 2,39 & 1,50 & 1,50 & 2,71 & 2,71 & 3,82 & 3,82 \\
\hline & 2,00 & 3,09 & 3,17 & 4,38 & 3,96 & 5,49 & 3,11 & 4,67 & 4,86 & 6,36 & 6,23 & 9,41 \\
\hline
\end{tabular}

FUENTE: MOPU, DGOH, Subdirección General de Explotación y Tecnología, Expedientes 203360, 530729, 619633 y 733484 y Departamento de Gestión del ATS (CHS).

Acueducto Tajo-Segura ${ }^{31}$. Hay que señalar, en este punto, que las acciones anti-tarifas fueron protagonizadas siempre por los usuarios de las aguas del trasvase con fines agrícolas; es decir, por los regantes, de ahí que el objetivo perseguido fuese siempre abaratar la

31 El primer antecedente del Sindicato fue la creación, en febrero de 1980, de un frente común de regantes, integrado por las comunidades de Riegos de Levante (margen izquierda), Lorca, Cartagena, Alhama, Librilla, Totana y Sangonera, que tenía como objetivo defender los intereses agrarios de los usuarios de las aguas del trasvase y evitar las luchas en solitario. Un año más tarde, en marzo de 1981, se creó la Comisión pro-Sindicato Central de Regantes del ATS, agrupando a una representación de cien mil hectáreas. En dicho Sindicato estarían representados las cinco comunidades de regantes de las zonas altas y media del Segura — Riegos de Levante (margen izquierda y derecha), Campo de Cartagena, Campo de Lorca, Bajo Guadalentín y Comunidad de Regantes de Mula - y todas aquellas que, aunque no rieguen con aguas del trasvase, utilicen los canales de la obra hidráulica en régimen de peaje. Se trataba, por lo tanto, de crear, de acuerdo con la Ley de Aguas de 1879, una «comunidad supra comunitaria». El Sindicato Central de Regantes del Acueducto Tajo-Segura quedó constituido en 1982, aprobándose su Reglamento por O.M. de 19 de noviembre de ese año. Formaban parte de él las entidades y usuarios de aguas conducidas por el ATS que fuesen titulares de derecho al uso del agua, ya hubiese sido éste adquirido por concesión, autorización o cualquier otro título jurídico. El Sindicato agrupaba a trece comunidades de regantes de 39 municipios de las provincias de Murcia y Alicante, con un total aproximado de 40.000 regantes y una superficie regada de más de 105.000 hectáreas, lo que lo configuraba como uno de los sindicatos de regantes más importantes del país, tanto por el número de afiliados como por la extensión superficial que englobaba. El órgano ejecutivo del Sindicato Central lo constituía una Comisión de Gobierno dirigida por el Presidente del Sindicato y formada por 15 miembros, en representación de las zonas y los intereses encuadrados en dicho organismo. Entre las atribuciones que le asignaba su Reglamento figuraban las siguientes: velar por los intereses de sus miembros, conciliar los intereses de las entidades de regantes encuadradas en el Sindicato, fomentar el estudio y la realización de proyectos que puedan beneficiar los intereses comunes y participar en todas las cuestiones derivadas del cumplimiento de la Ley de 1980, tales como controlar los caudales servidos o circulantes, informar sobre los componentes del precio del agua, la producción de energía y su coste, etc. 
tarifa de riego, aunque este abaratamiento repercutiese también en el agua para abastecimientos. Las primeras actuaciones del Sindicato se encaminaron a la negociación de tarifas, con el objetivo de reducir el coste del agua $^{32}$; para ello, trataron de promover las obras complementarias del trasvase, todavía por realizar, cuya construcción supondría una reducción de las tarifas. El Sindicato Central de Regantes del Acueducto Tajo-Segura se convirtió en el representante y principal valedor de los intereses de los regantes beneficiarios de las aguas del trasvase en la cuenca del Segura, actuando como el interlocutor frente a la administración central de las aguas, ya fuese en la Confederación Hidrográfica del Segura o en el Ministerio competente.

\section{Balance económico del ATS, 1979-1985}

El balance económico del trasvase depende de dos factores principalmente: las tarifas establecidas, a las que ya me he referido, y los volúmenes de agua conducidos por el ATS. Entre el 26 de mayo de 1979 y el 25 de agosto de 1981 se extendió el período conocido como pruebas del gestión. El resultado económico de las pruebas de gestión puede verse en el cuadro 4.

Cuadro 4

BALANCE ECONÓMICO DE LAS PRUEBAS DE GESTIÓN DEL ATS, 1979-1981

- INGRESOS:

Ptas

- Riegos (183.448.027 $\left.\mathrm{m}^{3} \mathrm{x} 4\right)$ 733.792 .108

- Abastecimientos $\left(98.967 .808 \mathrm{~m}^{3} \mathrm{x} 8\right)$ 791.742 .464

TOTAL 1.525.534.572

- GASTOS:

- C.H. del Segura 295.032 .173

- C.H. del Tajo 837.559 .743

- Anticipo de agua de la cuenca del Segura

- Pendiente de facturación para riego

- Pendiente de facturación para abastecimiento

TOTAL

FUENTE: CHS, Departamento de Gestión del ATS.

32 En este sentido, la actuación más importante de las llevadas a cabo por la Comisión fue la lucha contra la tarifa establecida el 31 de julio de 1981, que cifraba el precio del agua para riego en $6,71 \mathrm{ptas} / \mathrm{m}^{3}$ y para abastecimiento en $10 \mathrm{ptas} / \mathrm{m}^{3}$. La Comisión pro-constitución envió un escrito a la DGOH donde expresaba su total desacuerdo con las tarifas fijadas, aduciendo posibles errores en su cálculo. La lucha fue ganada por la Comisión y la DGOH hubo de reconocer que se habían cometido errores, rebajándose el precio del agua en 50 céntimos el metro cúbico. La DGOH respondió al escrito de la Comisión en los siguientes términos: «Que la CHS deduzca de los valores de las tarifas de conducción del agua del ATS aprobadas en Consejo de Ministros del 31 de julio de 1981 las cantidades siguientes:

a) $0,17 \mathrm{Ptas} / \mathrm{m}^{3}$ en el concepto c) debido a error material observado.

b) $0,33 \mathrm{Ptas} / \mathrm{m}^{3}$ en el concepto c) correspondientes a los sumandos $\mathrm{Cm}$, Cpe, de la fórmula establecida en la concesión otorgada a Unión Eléctrica, S.A. para la explotación reversible de Bolarque».

FUENTE: (MOPU, DGOH, Expediente 203360, fechado el 27 de enero de 1982). 


\section{Cuadro 5}

BALANCE ECONÓMICO DE LA EXPLOTACION DEL TRASVASE (C.H.T.) Y DEL POSTRASVASE (C.H.S.), 1979-1985

\begin{tabular}{|c|c|c|c|c|c|c|c|}
\hline & \multicolumn{3}{|c|}{ TRASVASE (CHT) } & \multicolumn{3}{|c|}{ POSTRASVASE (CHS) } & \multirow{2}{*}{$\frac{\text { TOTAL }}{(\mathrm{CHT}+\mathrm{CHS})}$} \\
\hline & INGRESOS & GASTOS & $I \cdot G$ & INGRESOS & GASTOS & $I \cdot G$ & \\
\hline 1979-81(1) & 837.559 .743 & 1.049 .489 .872 & -211.930 .129 & 1.525 .534 .572 & 1.264 .288 .970 & +261.245 .602 & +49.315 .473 \\
\hline 1981(2) & 376.012 .297 & 407.941 .632 & -31.929 .335 & 497.565 .616 & 533.017 .108 & -35.451 .492 & -67.380 .827 \\
\hline 1982 & 973.170 .739 & 1.339.481.506 & -366.310 .767 & 1.932.287.599 & 1.961 .437 .750 & -29.150 .151 & -395.460 .918 \\
\hline 1983 & 441.629 .574 & 641.060 .135 & -199.430 .561 & 1.117 .656 .423 & 1.173 .355 .877 & -55.699 .454 & -255.130 .015 \\
\hline 1984 & 676.047 .320 & 1.128.978.197 & -452.930 .877 & 1.601.555.499 & 1.739 .904 .838 & -138.349 .339 & -591.280 .216 \\
\hline 1984(3) & 1.055 .854 .000 & - & 1.055 .854 .000 & - & - & - & +1.055 .854 .000 \\
\hline \multirow[t]{2}{*}{1985} & 1.767 .445 .615 & 2.228.180.803 & -460.735 .188 & 2.984.342.598 & 3.166 .223 .048 & -181.880 .450 & -642.615 .638 \\
\hline & 6.127 .719 .288 & 6.795 .132 .145 & -667.412 .857 & 9.658.942.307 & 9.838.227.591 & -179.285 .284 & -846.698 .141 \\
\hline
\end{tabular}

(1) Desde el 26 de mayo de 1979 al 25 de agosto de 1981.

(2) Desde el 26 de agosto al 31 de diciembre de 1981.

(3) Subvención otorgada por el Ministerio de Hacienda.

FUENTE: CHT, Departamento de Explotación del ATS y CHS, Departamento de Gestión del ATS.

Elaboración propia.

Durante este período, el volumen trasvasado fue de $308,5 \mathrm{Hm}^{3}$, que, una vez descontadas las pérdidas por filtración y evaporación — cifradas en el 15\%-, dejó un caudal útil de 282,4 $\mathrm{Hm}^{3}$. La cantidad aplicada al riego $\left(183,4 \mathrm{Hm}^{3}\right)$ prácticamente dobló la destinada a abastecimientos $\left(98,9 \mathrm{Hm}^{3}\right)$; sin embargo, los ingresos por ambos apartados estuvieron muy igualados, superando los ingresos por abastecimientos en 58 millones a los correspondientes a los caudales de riego ${ }^{33}$. Durante este período, se partió de unos desembalses muy exiguos para llegar a un máximo de $155 \mathrm{Hm}^{3}$ en 1981. En cuanto a los gastos del ATS, un $23 \%$ fue abonado a la Confederación del Segura, en su mayor parte, para satisfacer el importe de los gastos fijos de funcionamiento del postrasvase y el coste de la energía utilizada para elevar el agua en el azud de Ojós y en la impulsión de Alhama. El 66\% de los ingresos fueron gestionados por la Confederación del Tajo, correspondiendo fundamental-

33 La distribución de caudales para riego y para abastecimientos, así como los ingresos anuales del ATS por ambos fue la siguiente:

\begin{tabular}{|l|c|c|c|c|}
\hline \multirow{2}{*}{} & \multicolumn{2}{|c|}{ ABASTECIMIENTOS } & \multicolumn{2}{c|}{ RIEGOS } \\
\cline { 2 - 5 } & $\mathbf{m}^{\mathbf{3}}$ & Ptas(=m3x8) & $\mathbf{m}^{\mathbf{3}}$ & Ptas(=m3x4) \\
\hline 1979 & 13.684 .720 & 109.477 .760 & 25.133 .154 & 100.532 .616 \\
1980 & 23.709 .354 & 189.674 .832 & 65.083 .769 & 260.335 .076 \\
\hline & 61.573 .734 & 492.589 .872 & 93.231 .104 & 372.924 .416 \\
& $\mathbf{9 8 . 9 6 7 . 8 0 8}$ & $\mathbf{7 9 1 . 7 4 2 . 4 6 4}$ & $\mathbf{1 8 3 . 4 4 8 . 0 2 7}$ & $\mathbf{7 3 3 . 7 9 2 . 1 0 8}$ \\
\hline
\end{tabular}

FUENTE: CHS, Departamento de Gestión del ATS. 
mente al pago de los usuarios de la parte de la tarifa en concepto del coste de las obras y de la mayor parte de los gastos variables, derivados sobre todo del coste de la energía. Las pruebas de gestión finalizaron con un superávit de 261 millones de pesetas.

Concluidas las pruebas de gestión, el día 25 de agosto de 1981, se inició la normal andadura del trasvase. En el cuadro 5 puede verse el balance económico de la explotación del trasvase, entre 1979 y $1985^{34}$.

Tanto el trasvase como el postrasvase presentan un balance deficitario desde el inicio de su explotación hasta el año 1985, con la sola excepción de las pruebas de gestión en el caso del postrasvase y del año 1979 en el del trasvase. Sin embargo, el déficit del trasvase que se eleva, si se descuenta la subvención que en 1984 le otorgó el Ministerio de Hacienda, a 1.723 millones de pesetas, para el período comprendido entre 1979 y 1985, es significativamente mucho mayor que el que arroja la gestión del postrasvase para ese mismo período (179 millones). La infrautilización que se hacía de las conducciones fue la principal razón del déficit, ya que al utilizar las obras para conducir un volumen de agua muy inferior a la capacidad para la que se habían proyectado disminuyó notablemente la rentabilidad de dichas obras. No hay que olvidar que el trasvase se construyó para desembalsar un total anual de $1.000 \mathrm{Hm}^{3}$, cifra que quedó reducida durante la primera fase a 600 $\mathrm{Hm}^{3}$ anuales; sin embargo, ambas cantidades quedaron muy lejos, como puede apreciarse en el cuadro 8, de los desembalses realizados entre 1979 y 1995. Esta infrautilización implicaba al menos dos cosas: una, que los gastos fijos de funcionamiento, que eran independientes del volumen de agua travasado, resultaban más difíciles de amortizar, repercutiendo en importantes subidas del precio del agua; $y$, dos, que las aportaciones de los usuarios por el concepto a) de la tarifa eran susceptiblemente menores a las previstas para esta $\mathrm{I}^{\mathrm{a}}$ fase. La reducción de los caudales del Tajo determinó un descenso de los ingresos, que cuestionó la rentabilidad del trasvase. El menor déficit del postrasvase tuvo que ver con su mayor grado de utilización, ya que por esta conducción no sólo circularon los caudales del Tajo, sino también los recursos propios de la cuenca del Segura, lo que aseguró un mayor ingreso por el cobro de tarifas a estos usuarios. El inicio de un prolongado período de sequía en 1980-81 contribuyó a agravar la situación, ya que, según la legislación, sólo podían trasvasarse los recursos excedentarios, que en esta situación, lógicamente, eran menores. Al mismo tiempo, los desembalses realizados implicaban una merma muy significativa de los caudales destinados al aprovechamiento hidroeléctrico en la cuenca del Tajo, lo que incrementaba los gastos de explotación del trasvase, ya que entre ellos se contaban las compensaciones económicas a las centrales hidroeléctricas por la energía que dejaban de producir debido a los trasvases de agua a la cuenca del Segura.

En el cuadro 6 pueden verse los gastos e ingresos del trasvase y del postrasvase durante el período 1979-85. La CHS ingresaba el importe total de la tarifa establecida para el metro cúbico de agua, suponiendo ésto el conjunto de los ingresos que se obtenían de la explotación del ATS; entre 1979 y 1985 los ingresos ascendieron a 9.658,2 millones de pesetas, de los cuales casi el $97 \%$ procedían del cobro de las tarifas de conducción del agua trasvasada para riegos y abastecimientos, aunque los recursos destinados a abastecimientos fueron inferiores a los utilizados para el riego, la mayor cuantía de la tarifa que gravaba el metro cúbico para abastecimiento determinó que los ingresos obtenidos por la asignación de estos recursos fuesen superiores a los conseguidos con la de riegos (4.450,3 millones frente a

34 El estudio sólo ha podido ser realizado hasta el año 1985, ya que hasta esa fecha los datos son absolutamente fiables, puesto que han sido validados y consolidados por la intervención del Ministerio de Hacienda. Los correspondientes a los años siguientes me los ha facilitado la CHS, pero sin las certificaciones del Ministerio de Hacienda. 


\section{Cuadro 6}

CUENTAS ANUALES DE EXPLOTACIÓN DEL TRASVASE (C.H.T.)

Y DEL POSTRASVASE (C.H.S.), 1979-1985. (Millones de pesetas)

\begin{tabular}{|c|c|c|c|c|c|c|c|c|c|}
\hline \multicolumn{10}{|c|}{ I. TRASVASE (CHT) } \\
\hline & \multirow{2}{*}{$\frac{\text { A. INGRESOS }}{\mathrm{m}^{3} \mathrm{x} \text { tarifa }}$} & \multicolumn{7}{|c|}{ B. GASTOS } & \multirow[b]{2}{*}{ TOTAL } \\
\hline & & \multicolumn{2}{|c|}{ Internos de explotación } & \multicolumn{2}{|c|}{ Canon de El Picazo } & \multicolumn{3}{|c|}{ Elevación al origen del ATS } & \\
\hline 1979 & 161,0 & \multicolumn{2}{|c|}{7,4} & \multicolumn{2}{|c|}{12,0} & \multicolumn{3}{|c|}{124,4} & 143,8 \\
\hline 1980 & 193,7 & \multicolumn{2}{|c|}{28,6} & \multicolumn{2}{|c|}{12,0} & \multicolumn{3}{|c|}{223,4} & 264,0 \\
\hline 1981 & 858,7 & \multicolumn{2}{|c|}{41,1} & \multicolumn{2}{|c|}{12,0} & \multicolumn{3}{|c|}{996,1} & $1.049,2$ \\
\hline 1982 & 973,1 & \multicolumn{2}{|c|}{106,2} & \multicolumn{2}{|c|}{12,0} & \multicolumn{3}{|c|}{$1.221,2$} & $1,339,4$ \\
\hline 1983 & 441,6 & \multicolumn{2}{|c|}{38,4} & \multicolumn{2}{|c|}{33,3} & \multicolumn{3}{|c|}{569,3} & 641,0 \\
\hline 1984 & 676,0 & \multicolumn{2}{|c|}{140,1} & \multicolumn{2}{|c|}{15,0} & \multicolumn{3}{|c|}{973,8} & $1.128,9$ \\
\hline 1985 & $1.767,4$ & \multicolumn{2}{|c|}{155,7} & \multicolumn{2}{|c|}{15,0} & \multicolumn{3}{|c|}{$2.072,4$} & $2.248,1$ \\
\hline \multicolumn{10}{|c|}{ II. POSTRASVASE (CHS) } \\
\hline \multicolumn{10}{|c|}{ A. INGRESOS } \\
\hline & Riegos Trasvase & Abastecimie & trasvase & Aguas pro & & & Almacén & & TOTAL \\
\hline $1979-81(1)$ & 733,7 & & & - & & & - & & $1.525,4$ \\
\hline 1981(2) & 261,6 & & & 0,4 & & & 157,2 & & 497,4 \\
\hline 1982 & 734,0 & 1.00 & & 26,3 & & & 164,8 & & $1.932,1$ \\
\hline 1983 & 394,0 & & & 18,1 & & & $-214,1$ & & $1.117,6$ \\
\hline 1984 & 743,5 & & & 39,4 & & & $-107,9$ & & $1.601,5$ \\
\hline 1985 & $1.583,5$ & 1.19 & & 102,8 & & & 107,9 & & $2.984,2$ \\
\hline B. GASTOS & & & & & & & & & \\
\hline & & OS Y VARIAB & & & & OMPONE & ENTE A) & & \\
\hline & CHS & CHT & Otros & Riegos & Abaste & cimientos & Propias & Almacén & TOTAL \\
\hline $1979-81(1)$ & 295,0 & 837,5 & 82,4 & - & & - & - & 49,2 & $1.264,1$ \\
\hline 1981(2) & 95,6 & 293,5 & - & 54,3 & & 7,7 & 0,1 & 51,6 & 532,8 \\
\hline 1982 & 288,0 & 973,1 & - & 152,4 & & 4,3 & 5,5 & 57,9 & $1.961,2$ \\
\hline 1983 & 277,0 & 441,6 & 17,5 & 77,7 & & 3,8 & 3,8 & $-78,2$ & $1.173,2$ \\
\hline 1984 & 439,5 & 676,0 & - & 146,6 & & 1,7 & 8,3 & 37,6 & $1.739,7$ \\
\hline 1985 & 575,5 & $1,767,4$ & - & 261,4 & & 7,9 & 17,7 & 66,2 & $3.166,2$ \\
\hline
\end{tabular}

(1) Desde 1 de enero a 25 de agosto de 1981.

(2) Desde 26 de agosto a 31 de diciembre.

FUENTE: CHT, Departamento de Explotación del ATS, Balances económicos anuales. C.H.S., Departamento de Gestión del ATS, Balances económicos anuales. 
4.913). Los ingresos totales recaudados por la CHS se fraccionaban en tres grandes apartados: uno encaminado a amortizar los gastos fijos y variables ocasionados por los desembalses en la cuenca del Tajo, esta cantidad se abonó a la CHT, siendo esta institución la encargada de su administración; otro, que se destinaba a costear los gastos fijos y variables que el funcionamiento del ATS generaba en la cuenca del Segura, estos ingresos eran los que realmente gestionaba la CHS; y, por último, el apartado resultante del pago del componente a) de las tarifas, que tenía como principal finalidad sufragar la ejecución de las obras compensatorias, aunque tambien podía destinarse a otros fines.

Los gastos del postrasvase, a lo largo del período comprendido entre el inicio de las pruebas de gestión y 1985, ascendieron a 9.837,2 millones de pesetas, correspondiendo más del 50\% de ellos - 4.989,1 millones- a los gastos fijos y variables de funcionamiento en la cuenca del Tajo, cantidad que fue transferida desde la Confederación del Segura a la del Tajo; el siguiente capítulo en importancia dentro de los gastos del postrasvase corresponde al pago al Estado por el concepto de amortización del coste de las obras, que supuso en el período analizado un importe de 2.777,5 millones de pesetas —más del $28 \%$ de los gastos del postrasvase-; de los cuales, una parte importante se destinó a la realización de obras compensatorias en las comunidades de Castilla-La Mancha, Madrid y Extremadura, y otra parte a enjugar el déficit del ATS. El capítulo menos importante, por su monto, de los que configuran los gastos del postrasvase fue el destinado a sufragar los gastos fijos y variables en la cuenca del Segura, que sumaban 1.970,6 millones. El desequilibrio entre los ingresos y los gastos generados por la explotación del postrasvase entre 1979 y 1985 arrojaba un saldo negativo de 179,2 milones de pesetas, según las cuentas realizadas por la CHS y consolidadas por el Ministerio de Economía y Hacienda.

En cuanto a los gastos del trasvase (CHT), cabe señalar la importancia de la partida destinada a sufragar el coste de la elevación del agua al origen del ATS: más del $90 \%$ del total de los gastos correspondían a este concepto y su importe se incrementó de forma muy notable desde 1979 (124,4 millones) hasta el año 1985 en que ascendió a 2.072,4 millones, lo que significó que la elevación del agua al origen del ATS pasó de costar 1,97 ptas $/ \mathrm{m}^{3}$ en 1979 a $5,81 \mathrm{ptas} / \mathrm{m}^{3}$ en 1985. Aunque en términos absolutos, el crecimiento de los gastos internos de explotación tienen menos importancia, si que es significativo este incremento en términos relativos, ya que se pasó de 7 millones en 1979 a 155 en 1985, elevándose el coste por este concepto de un metro cúbico de agua de 0,1 ptas a 0,4 . El pago del canon de peaje por la utilización del túnel de Picazo fue el gasto de los contemplados por la Confederación del Tajo que menor subida registró, con la excepción del año 1983 en que se elevó a más de 33 millones sin que, hasta el momento, sepa la causa de esta variación.

Ya he aludido al carácter negativo que presenta el balance del trasvase entre 1979 y 1985; en concreto, 667,4 millones de pesetas y ello, a pesar de haber recibido una subvención del Ministerio de Hacienda de más de mil millones. En conjunto trasvase y postrasvase presentaban a finales de 1985 un déficit de 846.698.141 pesetas. Para hacer frente a este déficit, el Consejo de Ministros, celebrado el 18 de abril de 1986, acordó que del importe total obtenido por la tarifa de conducción de agua correspondiente al coste de las obras se destinara la cantidad de 846.698 .141 pesetas a cubrir el déficit de explotación pendiente experimentado por las Confederaciones del Tajo y del Segura, desde el comienzo de los trasvases en 1979 hasta el 31 de diciembre de 1985, cantidad que se distribuyó proporcionalmente al saldo negativo presentado por cada una de ellas (179.285.284 para la CHS y 667.412.857 para la CHT). Ambos importes se incluyeron en el conjunto de la inversión estatal realizada hasta ese momento, acumulándose como gastos adicionales de la misma a efectos de la determinación del valor equivalente de la inversión, repercutible en las tarifas sucesivas a través del componente a). Los efectos se dejaron sentir en las tarifas aprobadas 


\section{Cuadro 7}

FACTURACIÓN DEL TRASVASE (INGRESOS) Y COMPONENTE a) DE LA TARIFA (GASTOS), 1979-1996

\begin{tabular}{|c|c|c|c|c|c|c|c|c|}
\hline & \multicolumn{4}{|c|}{ INGRESOS (Millones de ptas) } & \multirow{2}{*}{\multicolumn{4}{|c|}{$\begin{array}{l}\text { COMPONENTE A) DE LA TARIFA } \\
\text { (Millones de ptas) }\end{array}$}} \\
\hline & \multicolumn{3}{|c|}{ TRASVASE } & \multirow[t]{2}{*}{ PEAJE } & & & & \\
\hline & RIEGOS & ABASTEC. & TOTAL & & RIEGOS & ABASTEC. & PEAJES & TOTAL \\
\hline 1978-79 & 74,3 & 79,5 & 153,8 & - & - & - & - & - \\
\hline 1979-80 & 216,5 & 172,4 & 388,9 & - & - & - & - & - \\
\hline $1980-81$ & 557,5 & 561,9 & $1.119,4$ & 0,4 & 53,772 & 47,117 & 0,103 & 100,992 \\
\hline $1981-82$ & 831,6 & 843,9 & $1.675,5$ & 3,8 & 152,470 & 484,313 & 5,531 & 642,315 \\
\hline $1982-83$ & 438,9 & $1.007,9$ & $1.446,8$ & 40,6 & 77,719 & 464,762 & 3,821 & 546,303 \\
\hline 1983-84 & 611,9 & 907,4 & $1.519,3$ & 32,2 & 146,654 & 431,700 & 8,282 & 586,637 \\
\hline 1984-85 & $1.559,1$ & $1.092,4$ & $2.651,5$ & 98,8 & 261,421 & 477,935 & 17,734 & 757,091 \\
\hline $1985-86$ & $2.247,1$ & $1.544,1$ & $3.791,2$ & 152,2 & 495,785 & 750,731 & 33,828 & $1.280,356$ \\
\hline 1986-87 & $2.276,3$ & $1.987,5$ & $4.263,8$ & 174,6 & 598,036 & 951,418 & 37,783 & $1.587,237$ \\
\hline $1987-88$ & $2.345,0$ & $2.016,5$ & $4.361,9$ & 145,3 & 648,262 & $1.002,481$ & 36,348 & $1.687,092$ \\
\hline 1988-89 & $2.651,7$ & $2.407,5$ & $5.059,2$ & 180,1 & 551,430 & $1.006,010$ & 31,866 & $1.589,307$ \\
\hline $1989-90$ & $1.789,4$ & $2.282,3$ & $4.071,7$ & 382,1 & 402,762 & 910,802 & 78,017 & $1.391,582$ \\
\hline $1990-91$ & $2.363,5$ & $2.447,9$ & $4.811,4$ & 546,9 & 514,175 & 999,892 & 91,300 & $1.605,368$ \\
\hline 1991-92 & $1.363,2$ & $2.234,6$ & $3.597,8$ & 197,8 & 181,234 & 909,218 & 35,266 & $1.125,719$ \\
\hline $1992-93$ & 772,5 & $2.242,1$ & $3.014,6$ & 161,3 & 161,523 & 913,406 & 31,630 & $1.106,559$ \\
\hline 1993-94 & $1.148,2$ & $2.296,5$ & $3.444,7$ & 120,1 & 278,739 & 960,865 & 21,221 & $1.260,826$ \\
\hline 1994-95 & 540,4 & $2.253,2$ & $2.793,6$ & 119,4 & 122,730 & 927,253 & 24,311 & $1.074,306$ \\
\hline 1995-96 & $3.664,9$ & $2.648,0$ & $6.312,9$ & 293,2 & 827,464 & $1.089,203$ & 55,774 & $1.972,442$ \\
\hline
\end{tabular}

FUENTE: Departamento de Gestión del ATS (CHS).

en 1986, en las cuales se produjo un fuerte incremento de la cantidad que debían abonar los usuarios por el componente a), que prácticamente se duplicó en todos los casos, como puede verse en el cuadro 3. En el acuerdo de Consejo de Ministros se estableció que si se volvían a producir resultados negativos en la explotación del ATS, deberían ser cubiertos con mecanismos distintos, es decir, no se podría aplicar a este fin lo recaudado por el componente a), ya que la totalidad del cobro de este concepto debería asignarse a la ejecución de obras hidráulicas en la cuenca del Tajo y provincias afectadas ${ }^{35}$.

35 Acuerdo de Consejo de Ministros sobre las recaudaciones obtenidas en el Trasvase Tajo-Segura correspondientes al concepto de aportación por el coste de las obras, DGOH, Subdirección General de Explotación y Tecnología, Expediente 621171, 20 de mayo de 1986. 
El importe remanente de la recaudación obtenido por el cobro del componente a) de la tarifa hasta el 31 de diciembre de 1985 se destinó a la realización de inversiones en obras hidráulicas y de ingeniería sanitaria en los territorios de las Comunidades de Castilla-La Mancha, Madrid y Extremadura, de acuerdo con el siguiente desglose: 987.324 .895 ptas para obras especificadas en la Ley de 1971 o sus sustitutivas, esta recaudación procedía de las tarifas de riego; y 808.208.566 ptas para obras de ingeniería sanitaria, este dinero era el recaudado por abastecimientos. Las proporciones de distribución entre las Comunidades se establecieron de la siguiente manera: 4/9 para Castilla-La Mancha, 3/9 para Madrid y 2/9 para Extremadura; regulándose que, en lo sucesivo, las cantidades que se obtuvieran por la aportación al coste de las obras se distribuyeran de acuerdo con las anteriores proporciones.

A partir del año 1985, no dispongo de cuentas consolidadas de ingresos y gastos del ATS. Tan sólo tengo referencia de los ingresos a partir de las cantidades facturadas por el trasvase; cantidades que son el resultado de multiplicar los volúmenes de agua trasvasados o conducidos por el acueducto por las respectivas tarifas vigentes. Las cuentas de facturación vienen dadas por años hidrológicos (octubre a septiembre) y se diferencian los ingresos según se trate de aguas trasvasadas para riegos o abastecimientos y el peaje de conducción de aguas propias de la cuenca del Segura. De los gastos, tan sólo se reseñan los correspondientes a la aportación al coste de las obras por el concepto a) de la tarifa, diferenciándose los derivados del uso del agua del Tajo para riego y los de abastecimientos. Como puede apreciarse en el cuadro 7, los ingresos del trasvase continuaron elevándose hasta el año 1988-89, en que se inició una tendencia descendente que culminó en 199495; año en que la facturación del trasvase se equiparó con el nivel de 1984-85. La evolución de los ingresos y de la recaudación por el concepto a) estuvo determinada por los volúmenes que circularon por el trasvase.

Los trasvases de agua del Tajo a la cuenca del Segura se iniciaron el 31 de marzo de 1979. Las expectativas generadas por este primer desembalse fueron tales, que, en opinión de los técnicos y de las autoridades hidráulicas, esta obra triplicaría la zona regable, resolvería definitivamente el problema del abastecimiento e impulsaría el desarrollo industrial y turístico de las zonas receptoras. Sin embargo, las esperanzas despertadas pronto se vieron limitadas por el recorte de los volúmenes enviados. En la tabla de volúmenes trasvasados se observa que al Segura han llegado menos de la mitad de los caudales previstos para la $I^{a}$ Fase. La máxima de este período correspondió al año 1986-87 con $377,2 \mathrm{Hm}^{3}$. La importancia de los caudales del Tajo radicó en que sirvieron para limitar los efectos de una etapa extremadamente seca en la cuenca del Segura. Una situación que se mantuvo de forma prolongada, lo que significó un recrudecimiento de las dificultades. Los caudales del Tajo fueron destinados prioritariamente a los abastecimientos de poblaciones, que no sufrieron restricciones; por el contrario, la escasez de agua para riego incidió de forma muy negativa en las cosechas y paralizó el desarrollo de las zonas regables. Desde el Segura se culpó a la mala administración de los recursos que se hacía en la cuenca del $\mathrm{Tajo}^{36}$. La mejoría de la situación metereológica de la cuenca del Tajo permitió incrementar los volúmenes trasvasados a partir de 1984-85; pero, en lo sucesivo, cada autorización de un trasvase de aguas del Tajo al Segura fue fuertemente protestada desde la cuenca

36 Así, el Presidente del Sindicato Central de Regantes del ATS afirmaba: «El problema está en la mala administración del agua del Tajo, ya que si las necesidades anuales para los usuarios del Tajo que dependen de los embalses de cabecera son, según la DGOH, de $517 \mathrm{Hm}^{3}$, en cuatro años esas necesidades suman $2.069 \mathrm{Hm}^{3}$. En los cuatro años hidrológicos que van del 77-78 al 80-81 se dembalsaron 5.013 $\mathrm{Hm}^{3}$, lo que indica que ha habido un desembalse en exceso de $2.945 \mathrm{Hm}^{3} »$. 


\section{Cuadro 8}

VOLÚMENES CIRCULANTES POR EL TRASVASE, 1978-79/1995-96. En Hm

\begin{tabular}{|c|c|c|c|c|c|}
\hline \multirow{2}{*}{ AÑOS } & \multicolumn{4}{|c|}{ RECURSOS DEL TRASVASE } & \multirow{2}{*}{$\begin{array}{c}\text { RECURSOS PROPIOS DE } \\
\text { LA CUENCA DEL SEGURA } \\
\text { (PEAJE) }\end{array}$} \\
\hline & $\begin{array}{l}\text { Volúmenes } \\
\text { trasvasados }\end{array}$ & $\begin{array}{l}\text { Volúmenes efectivos } \\
\text { (Menos pérdidas) }\end{array}$ & Riegos & Abastecimientos & \\
\hline $1978-79$ & 63,2 & 28,4 & 18,5 & 9,9 & - \\
\hline $1979-80$ & 36,0 & 75,6 & 54,1 & 21,5 & - \\
\hline $1980-81$ & 253,1 & 198,7 & 129,3 & 69,4 & 0,2 \\
\hline $1981-82$ & 344,6 & 222,7 & 133,9 & 88,8 & 1,9 \\
\hline $1982-83$ & 94,1 & 170,5 & 67,5 & 103,0 & 20,3 \\
\hline $1983-84$ & 141,1 & 185,8 & 93,5 & 92,3 & 16,1 \\
\hline $1984-85$ & 349,7 & 291,4 & 193,2 & 98,2 & 36,9 \\
\hline $1985-86$ & 353,0 & 311,2 & 206,1 & 105,1 & 41,5 \\
\hline $1986-87$ & 377,2 & 313,3 & 194,5 & 118,8 & 44,1 \\
\hline $1987-88$ & 375,4 & 320,9 & 200,4 & 120,5 & 36,7 \\
\hline $1988-89$ & 347,3 & 328,2 & 197,2 & 131,0 & 37,7 \\
\hline $1989-90$ & 250,0 & 251,7 & 130,7 & 121,0 & 78,4 \\
\hline $1990-91$ & 300,0 & 302,5 & 172,7 & 129,8 & 112,3 \\
\hline $1991-92$ & 247,0 & 218,1 & 99,6 & 118,5 & 40,6 \\
\hline $1992-93$ & 185,0 & 175,3 & 56,4 & 118,9 & 33,1 \\
\hline 1993-94 & 250,0 & 205,7 & 83,9 & 121,8 & 24,6 \\
\hline $1994-95$ & 191,5 & 158,3 & 39,4 & 119,5 & 24,5 \\
\hline $1995-96$ & 372,7 & 311,8 & 201,3 & 110,5 & 47,1 \\
\hline SUMA & $4.375,0$ & $4.072,3$ & $2.273,1$ & $1.799,2$ & 596,5 \\
\hline
\end{tabular}

FUENTE: Departamento de Gestión del ATS (CHS).

cedente, lo que reactivó el ya tradicional enfrentamiento entre ambas cuencas. Cualquier acontecimiento servía para encrespar el tema del trasvase, cuando parecía que el régimen de desembalses se iría normalizando paulatinamente ${ }^{37}$. Desde la cuenca del Segura se pedía que se normalizasen los envíos y que progresivamente éstos se acercaran a la cantidad

37 En este contexto, cabe mencionar el informe sobre el trasvase elaborado por la oficina del Defensor del Pueblo a petición de Castilla-La Mancha. En él se afirmaba lo siguiente: «La mayoría de los expertos consultados estiman que el trasvase era necesario y rentable y, que, finalizada prácticamente la ejecución de las obras, resulta inviable plantear una alternativa antitrasvase». El trasvase era «irreversible», según el Defensor del Pueblo, lo que significaba un espaldarazo para los intereses de la cuenca del Segura. 
prevista en la $\mathrm{I}^{\mathrm{a}}$ fase $^{38}$, también se solicitaba que los caudales llegasen cuando fueran necesarios. Las zonas regables del trasvase siguieron desarrollándose a medida que crecían los envíos del Tajo, por lo que la demanda para riego se amplió. La necesidad de adecuar la realidad a la legalidad y de poner fin a las ampliaciones incontroladas fue la base del R.D. de 30-12-1986, mediante el cual se ordenaron los regadíos de la cuenca del Segura. En 1989-90, se inició una nueva etapa de sequía que coincidió con la llamada «guerra del agua» entre las comunidades de Castilla-La Mancha y Murcia. Los envíos del Tajo se redujeron hasta las cantidades para satisfacer las necesidades mínimas de la cuenca del Segura, prolongándose esta situación hasta 1995-96, en que se volvieron a incrementar los volúmenes trasvasados. La reducción de los caudales fue especialmente fuerte en el caso de los regadíos —el mínimo del año 1994-95 $\left(39,4 \mathrm{Hm}^{3}\right)$ sólo ha sido superado por el desembalse correspondiente al primer año de funcionamiento del ATS- Ante la imposibilidad de rebajar los recursos para atender el abastecimiento urbano, el consumo para riego se limitó al agua sobrante.

Estas limitaciones de los recursos trasvasados estuvieran motivadas por la deficiente planificación en la cabecera del Tajo. Según J. Andreu Álvarez (1997), junto con el diseño de la estructura del trasvase, no se creó ningún tipo de regla de explotación del sistema de cabecera del Tajo; el agua que aportaba ésta en los años previos al funcionamiento del trasvase, debidamente gestionada, hubiera permitido pasar sin apuros la sequía que se presentó en los años 1980-83. De forma similar, las aportaciones de los años 1984-91, debidamente gestionadas, hubieran servido para paliar, si no totalmente, si en gran medida, la última sequía. Parte del agua que hubiera podido ser almacenada para épocas de sequía fue utilizada en otros usos, aguas abajo del Tajo. Según la Regla de Explotación propuesta por la CHT en el último borrador del Plan Hidrológico de la cuenca del Tajo (1995), si se aplicara de forma escrupulosa y se repitieran las series históricas de precipitaciones en la cabecera sería posible durante los 83 años de explotación suministrar una media de 513 $\mathrm{Hm}^{3}$ y durante los años más duros del final del período no se bajaría de los $370 \mathrm{Hm}^{3} /$ año.

El principal destino de los caudales enviados desde el Tajo, con excepción de los dos períodos de sequía, fue el regadío, derivándose para tal fin entre el 60 y el $70 \%$ del total de los trasvases. A partir del año 1984-85, el volumen destinado a riegos se estabilizó en unos $200 \mathrm{Hm}^{3} /$ año, hasta que en 1991-92, con el inicio de una nueva etapa seca y debido a la prioridad del abastecimiento, la proporción de aguas trasvasadas para la agricultura se redujo, situándose durante los últimos años sólo alrededor del 40\%. La planificación inicial preveía una proporción inversa, que asignaba al uso agrícola el 79\% del volumen trasvasado (CES, 1995: 72). Los caudales para abastecimientos se incrementaron en el transcurso del período analizado, llegando a rebasar la cifra máxima que la Ley de 1980 preveía para este fin durante la I ${ }^{\mathrm{a}}$ fase de explotación del ATS. Así, aunque este máximo se situaba en $110 \mathrm{Hm}^{3}$ de los $600 \mathrm{Hm}^{3} /$ anuales a derivar del Tajo, y en ningún año se llegó a esta cifra

38 En 1985, ante la falta de normalización de la explotación del ATS, el Presidente de la CHS —E. Pérez (1988: 50) - señalaba una serie de medidas que, en su opinión, facilitarían la consolidación de la I a fase y la consecución, aunque fuera sólo en parte, del comienzo de la II ${ }^{\mathrm{a}}$. Estas medidas eran:

- Construcción de un canal del Jarama al Tajo, para aumentar los volúmenes de este segundo río, aguas arriba de Aranjuez, donde estaban los regadíos y el compromiso de paso de $6 \mathrm{~m}^{3} / \mathrm{seg}$. por razones ecológicas.

- Realización de un trasvase del Alberche al Guadarrama, para atender los regadíos de Sagra-Torrijos (cuenca del Tajo).

- Construcción de la torre de refrigeración de la central nuclear de Zorita, que supondría un gasto insignificante en comparación con la inversión realizada para mejorar la central nuclear.

- Mejora del regadío de Aranjuez, con la aportación financiera de los regantes del trasvase (componente a), que se beneficiarían de los volúmenes de agua liberados al realizar la mejora. 
tope, la cantidad destinada a satisfacer la demanda urbana ha superado esa cantidad desde el año 1986-87 hasta la actualidad. Ello fue consecuencia, primero, de los excepcionales años de sequía que sufrió la cuenca del Segura, que provocaron una importante disminución de los caudales en la cabecera de los ríos Segura y Taibilla — principales suministradores de recursos de la Mancomunidad de los Canales del Taibilla-, lo que hizo que tuviera que recurrirse al trasvase para paliar esta situación. Pero, además de la situación de sequía, otro hecho contribuyó a que se incrementaran los recursos trasvasados para abastecimientos, fue el aumento de la demanda de agua para usos urbanos e industriales que se produjo en la décadas de los 80-90 y que tuvo que ver no sólo con la expansión de la red de distribución, que cada vez afectó a zonas más amplias, sino también con el proceso de crecimiento económico experimentado en la cuenca del Segura durante estos años; proceso que se materializó en una notable expansión urbana, el auge de determinadas industrias y, sobre todo, el fuerte crecimiento del sector turístico. Todo ello implicó unas mayores necesidades de agua para abastecimiento, que difícilmente podían ser satifechas con los recursos propios de la cuenca ${ }^{39}$.

Por su parte, el análisis provincial de los destinos del agua trasvasada confirma a las provincias de Murcia y Alicante como las principales beneficiarias, tal como se establecía en la Ley de 1980. La comarca almeriense del Valle del Almanzora resultó afectada en menor medida en esta $\mathrm{I}^{\mathrm{a}}$ fase, asignándosele tan sólo un máximo de $15 \mathrm{Hm}^{3} /$ año para riegos. Lógicamente, el desarrollo alcanzado por el regadío de cada zona guardó una relación directa con el volumen de agua para riego consumido por cada una. Así, fueron Riegos de Levante M.I., el Campo de Cartagena y el Valle del Guadalentín las zonas que mayor superficie de regadío desarrollaron y, por tanto, también, las que mayor volumen de agua consumieron ${ }^{40}$. En conjunto, las hectáreas regadas con agua del trasvase en la cuenca del Segura, a finales de los años ochenta, sumaban unas 136.000 hectáreas, según los datos del SCR del ATS. Un estudio de J. Aranda, A. Martínez y J. Rodríguez (1992: 172) cuantifica los ingresos brutos generados por los nuevos cultivos en la zona del trasvase de la región de Murcia en torno a 55.000 millones de pesetas al año, situando los ingresos obtenidos en función de los caudales consumidos, por término medio, en 210 pesetas $/ \mathrm{m}^{3}$.

\section{Conclusiones}

La actual etapa de la planificación hidrológica se basa en los siguientes criterios generales: la titularidad estatal del dominio hidráulico, la consideración de que sólo pueden transferirse los recursos excedentarios o sobrantes de la zona de origen, la condición de que las actuaciones emprendidas deben reportar un beneficio general a la sociedad, la política de compensaciones a la cuenca cedente y el cumplimiento de criterios económicos que avalen la rentabilidad de las obras. El trasvase Tajo-Segura puede ser considerado, en este sentido, como un claro antecedente de la planificación hidrológica.

El régimen económico de la explotación del ATS se reguló con la Ley de 1980. Ésta estableció un sistema de tarifas con el que se perseguía que los usuarios fuesen los que corriesen con las inversiones y con los gastos de explotación y conservación de las

39 No en vano, en 1968, cuando se aprobó el proyecto del trasvase, se abrió la posibilidad de que la MCT se beneficiara del mismo, tomándose el trasvase como la base sobre la que se sustentó el Plan de Ampliación de los Abastecimientos en la Cuenca del Segura. Un análisis de la importancia que las aguas del trasvase han tenido para el desarrollo de los abastecimientos urbanos puede verse en A. Morales Gil y F. Vera Rebollo (1989: 45-48).

40 Entre las tres sumaban el $67 \%$ del total de las hectáreas afectadas por el trasvase y el $75,7 \%$ del agua de riego consumida entre 1978-79 y 1986-87. (J. Melgarejo, 1993). 
instalaciones, buscando la autosuficiencia, al tiempo que la obtención de recursos adicionales para el cumplimiento de las obligaciones compensatorias con la cuenca cedente. El componente a) de la tarifa era una novedad en el sistema de financiación de las obras hidráulicas por el Estado y levantó fuertes protestas entre los usuarios de la cuenca del Segura. La novedad radicaba en que desaparecía el principio de ayuda del Estado y no se fijaba plazo de amortización. La aportación de los usuarios, por este concepto, se estipulaba como un peaje a perpetuidad, determinado por la inversión realizada, actualizada de acuerdo con la inflación.

El precio del agua conducida por el trasvase se incrementó de forma notable durante el período analizado (1979-1995), como consecuencia, sobre todo, de las diferentes actualizaciones que se realizaron del coste de las obras y de las fuertes subidas que registró el precio de la energía utilizada para elevar el agua. Por ello, no resulta extraño que fueran estos dos conceptos los más protestados por los afectados.

El balance económico de la explotación del trasvase, entre los años 1979 y 1985, fue deficitario, con la única excepción de las pruebas de gestión. La principal causa del déficit fue la infrautilización que se hizo, y se sigue haciendo, de unas obras concebidas para trasvasar mayores caudales de los que se han conducido hasta el momento. De los 600 $\mathrm{Hm}^{3} / a n ̃ o ~ q u e ~ e s t a b a n ~ p r e v i s t o s ~ e n ~ l a ~ I^{\mathrm{a}}$ fase - las obras estaban proyectadas para 1.000 $\mathrm{Hm}^{3} /$ año- , a la cuenca del Segura han llegado a razón de una media de $250 \mathrm{Hm}^{3} / a$ ano, con el consiguiente encarecimiento de los gastos de explotación por $\mathrm{m}^{3}$. La utilización del postrasvase para conducir recursos propios, además de los trasvasados, ha contribuido a equilibrar su régimen económico, al incrementar los ingresos de explotación. Cabe señalar que una mejor gestión en la cabecera del Tajo hubiera paliado el déficit, ya que habría permitido incrementar los envíos y, con ello, maximizar la rentabilidad de la infraestructura. Por otra parte, la cicatería de la Administración a la hora de reducir la inversión en la infraestructura básica del trasvase también ha supuesto una carga suplementaria para la explotación de la obra y, en ocasiones, una supeditación de los usuarios del trasvase a los intereses de las hidroeléctricas, con las consiguientes repercusiones negativas para el buen funcionamiento del trasvase.

En cualquier caso, lo que está fuera de toda duda es que la llegada de las aguas del Tajo a la cuenca del Segura ha contribuido a aliviar la situación de carestía crónica que padecía esta zona, generando un proceso de desarrollo económico en estas tierras. Ahora bien, el déficit de agua y la falta de ordenación de los aprovechamientos siguen siendo los dos problemas básicos que presenta la explotación del trasvase. La demanda de las aguas del trasvase ha crecido, tanto para abastecimiento como para riego, por delante de la oferta. La imprecisión en la definición de las aguas excedentarias se ha convertido en el centro de la disputa que enfrenta a la zona cedente con la receptora. Tras casi dos décadas de trasvase, todavía no se ha llegado a culminar la $\mathrm{I}^{\mathrm{a}}$ fase de explotación y continua cuestionándose el suministro de recursos. La incertidumbre sobre los volúmenes a trasvasar cada año ejerce una influencia muy negativa sobre las actividades económicas que se sustentan en ellos, ya que no puede plantearse cada año hidrológico como una aventura económica, sobre todo cuando el nivel de las inversiones realizadas es muy elevado. Por ello, se hace necesario que se cumpla la legislación vigente y que la incertidumbre física se reduzca mediante el almacenamiento de agua de una estación a otra y de un año a otro. La función de almacenar en los años de bonanza para suministrar agua en los de sequía no se ha conseguido, por lo que cabría plantearse una mejor utilización de los llamados embalses hiperanuales.

Como dijo Juan Benet (El País, 14-3-1984): «Del trasvase Tajo-Segura se puede decir todo lo que se quiera menos que se trata de una obra gratuita e innecesaria (...) Si ha suscitado tanta polémica se debe, en buena medida, a su singularidad, a que no ha venido 
acompañada de otras equivalentes que poco a poco hayan formado ese mecanismo y a la atrasada manera de pensar de mucha gente que sigue creyendo todavía en la propiedad territorial del agua».

\section{Bibliografía}

ANDREU ÁLVAREZ, J. (1997): «Importancia de una gestión racional de los recursos hídricos para la viabilidad de transferencias entre cuencas», Jornadas Internacionales: Agua Horizonte 2005, Murcia.

ARANDA, J.; MARTÍNEZ, A. y RODRÍGUEZ, J. (1992): El agua, base del desarrollo de la Región de Murcia, Consejo de Cámaras Oficiales de Comercio, Murcia.

CABALLER, V. y GUADALAJARA, N. (1998): Valoración económica del agua de riego, Ediciones Mundi Prensa, Barcelona-México.

CES (1995): Recursos hídricos y su importancia en el desarrollo de la Región de Murcia, Murcia.

CONSEJERÍA DE POLÍTICA TERRITORIAL Y OBRAS PÚBLICAS (1984): El aprovechamiento energético de los recursos hidráulicos en la cuenca del Segura y los relacionados con la explotación del trasvase Tajo-Segura, Comunidad Autónoma de Murcia, Murcia.

GONZÁLEZ ROMERO, A. y RUBIO, S. (1993): «El problema de la planificación hidrológica: una aplicación al caso español», Revista de Economía Aplicada, $\mathrm{n}^{\circ} 1$.

JUÁREZ SÁNCHEZ-RUBIO, C. (1991): Planificación hidrológica y desarrollo económico: el Trasvase Tajo-Segura, Instituto de Cultura «Juan Gil-Albert», Alicante.

MAC DONNELL, L. y HOWE, Ch.W. (1992): en F. AGUILERA KLINK, Economía del Agua, MAPA, Madrid.

MARTÍN MENDILUCE, J.M. (1989): «Planificación de recursos hidráulicos españoles», Revista de Obras Públicas, $\mathrm{n}^{\circ} 14$.

MELGAREJO MORENO, J. (1993): La política hidráulica: la Confederación Hidrográfica del Segura. Tesis Doctoral, Universidad de Murcia.

- (1995): La intervención del Estado en la cuenca del Segura, Instituto de Cultura «Juan GilAlbert», Alicante.

- (1997): «El Trasvase Tajo-Segura en el centro de la tormenta política de la transición», Áreas, $\mathrm{n}^{\circ}$ 17.

MENÉNDEZ REXACH, A. (1986): «La Ley de aguas de 13 de junio de 1879 y la evolución posterior», en A. GALLEGO ANABITARTE; A. MENÉNDEZ REXACH y J.M. DÍAZ LEMA, El derecho de aguas en España, MOPU, Madrid.

MORALES GIL, A. y VERA REBOLLO, F. (1989): La Mancomunidad de los Canales del Taibilla, Murcia.

NICOLÁS MARTÍNEZ, J.L. (1995): «Trasvase Tajo-Segura», en M. SENENT (Dir.), A gua y futuro en la Región de Murcia, Asamblea Regional de Murcia, Murcia.

PÉREZ PÉREZ, E. (1988): Crónica de una cuenca sedienta, CAM, Murcia.

SANDOVAL RODRÍGUEZ, J.M. (1989): El Trasvase Tajo-Segura: solución al desequilibrio hidrológico, Nuevos Enfoques, Madrid.

TORRES, M. de (1959): El regadío murciano problema nacional, IOATS, Murcia. 
